\begin{tabular}{|l|l|}
\hline $\begin{array}{l}\text { 2. To: (Receiving Organization) } \\
\text { FSAR Development }\end{array}$ & $\begin{array}{l}\text { 3. From: (Originating Organization) } \\
\text { Safety Is sue Resolution }\end{array}$ \\
\hline 5. Proj./Prog./Dept./Div.: & $\begin{array}{l}\text { 6. Design Authority/ Design Agent/Cog. } \\
\text { Engr.: }\end{array}$ \\
\hline
\end{tabular}

8. Originator Remarks:

The subject document is the technical basis (topical) report in support of the Hanford Site Tank Farms Final Safety Analysis Report (FSAR). This technical basis concludes that the waste contents are subcritical and that under current plutonium inventories and operating conditions, a nuclear criticality accident is incredible.
11. Receiver Remarks:
11A. Design Baseline Document?

4. Related EDT No.:
N/A
7. Purchase Order No.:
N/A

9. Equip./Component No.:

$\mathrm{N} / \mathrm{A}$

10. System/Bldg./Facility:

$N / A$

12. Major Assm. Dwg. No.:

$N / A$

13. Permit/Permit Application No.: $N / A$

14. Required Response Date:

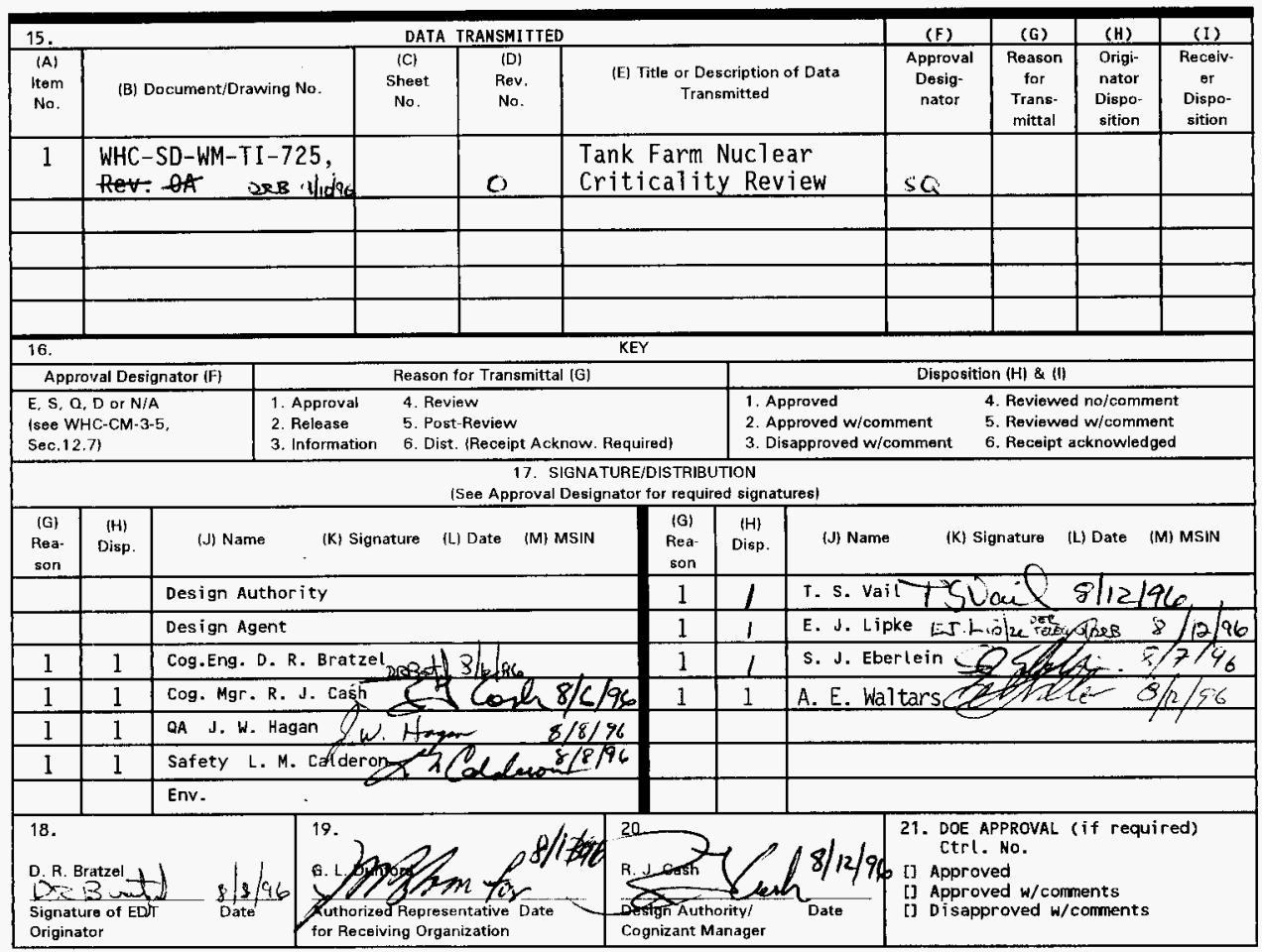

BD-7400-172-2(05/96) GEF097 


\title{
Tank Farm Nuclear Criticality Review
}

WHC-SD-WM-TI-725 REV 0

\author{
Principal Authors: \\ D. R. Bratzel \\ West inghouse Hanford Company, Richland, WA 99352 \\ W. H. Schulz \\ W2S Company, Albuquerque, NM 87111 \\ R. Vornehm \\ M. H. Chew \& Associates, Richland, WA 99352 \\ Expert Criticality Team Authors: \\ A. E. Walt tar \\ H. Babad \\ G. S. Barney \\ J. Greenborg \\ L. H. Rodgers \\ West inghouse Hanford Company, Richland, WA 99352 \\ R. E. Felt \\ U.S. Department of Energy, EH-34 \\ Contributing Authors: \\ D. W. Jeppson \\ C. A. Rogers \\ K. N. Schwinkendorf \\ T. S. Vail \\ West inghouse Hanford Company, Richland, WA 99352 \\ R. J. Serne \\ G. A. Whyatt \\ Pacific Northwest National Laboratory, Richland, WA 99352
}

U.S. Department of Energy Contract DE-AC06-87RL10930

U.S. Departiont $4,3 \% 7$

EDT/ECN: 603229 x

Org Code: 8M700 Charge Code: N1696

B\&R Code: EW3120071 Total Pages: 65

Key Words: Hanford site tank farms, criticality safety basis, fissile materials

Abstract:

The technical basis for the nuclear criticality safety of stored wastes at the Hanford Site Tank Farm Complex was reviewed by a tearn of senior technical personnel whose expertise covered all appropriate aspects of fissile materials chemistry and physics. The team concluded that the detailed and documented nucleonics-related studies underlying the waste tanks criticality safety bas is were sound. The team concluded that, under current plutonium inventories and operating conditions, a nuclear criticality accident is incredible in any of the Hanford single-shell tanks (SST), double-shell tanks (DST), or double-contained receiver tanks (DCRTs) on the Hanford Site.

TRADEMARK DISCLAIMER. Reference herein to any specific commercial product, process, or service by trade name, trademark, manufacturer, or otherwise, does not necessarily constitute or imply its endorsement, recommendation, or favoring by the United States Government or any agency thereof or its contractors or subcontractors.

Printed in the United States of America. To obtain copies of this document, contact: WHC/BCS Document Control Services, P.O. Box 1970, Mail stop H6-08, Richland WA 99352, Phone (509) 372-2420; Fax (509) 376-4989.

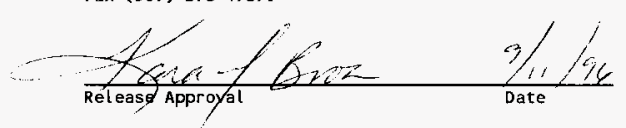

Approved for Public Release

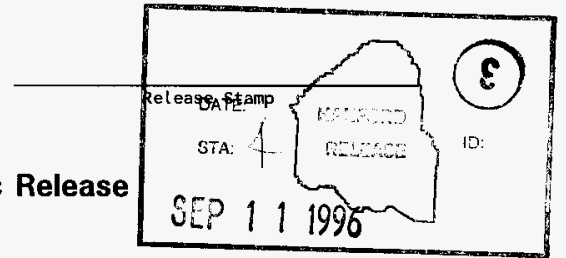


WHC-SD-WM-TI-725

Revision 0

\section{EXECUTIVE SUMMARY}

A team of senior technical personne1, whose expertise covered all relevant aspects of fissile materials chemistry and physics, reviewed the technical basis for the nuclear criticality safety of waste stored in underground tanks at the Hanford Site. This report documents significant technical bases and findings of the senior review team. The team concluded that, under current plutonium inventories and operating conditions, a nuclear criticality accident is incredible in any of the Hanford Site single-shell tanks (SST), double-shell tanks (DST), or double-contained receiver tanks (DCRT) .

To establish a technical basis for safe subcritical storage of wastes in SSTS, DSTS, and DCRTs, the team examined the neutronics of the waste tank system and chemical and hydraulic factors related to initial deposition of wastes in the tanks, aging of the wastes, and behavior of the wastes under established operating conditions (e.g., salt well pumping, etc.). From a neutronics standpoint, nuclear criticality of the tank waste contents is a function of four important parameters:

- Fissile material quantity and concentration

- Neutron absorbers--type and amount

- Waste geometry

- Neutron moderation.

The first two parameters are particularly important with respect to an accidental criticality of the tank waste contents. Collectively, the SSTs and DSTs contain an estimated 500 to $1,000 \mathrm{~kg}$ of plutonium. Analyses of tank 
waste samples from several tanks clearly establish that the plutonium content of the waste in any tank is associated almost exclusively with the sludge phase. The maximum measured plutonium concentration in a sludge phase is about $0.35 \mathrm{~g} / \mathrm{L}$ (a single data point of $0.7 \mathrm{~g} / \mathrm{L}$ has been measured for tank 241-SY-102), which is below the minimum subcritical concentration of $2.6 \mathrm{~g} \mathrm{Pu} / \mathrm{L}$ conservatively derived for tank waste conditions. In most of the SSTs and DSTs, the plutonium concentration in the sludge phase is at least 100 times less than $2.6 \mathrm{~g} \mathrm{Pu} / \mathrm{L}$. These conditions reflect the deliberate controls exercised throughout operation of fuel reprocessing and purification facilities to maintain the plutonium concentration in waste streams to very low levels.

Figure ES-1 is a summary graphic representation of the significant margin of subcriticality of the waste. The graphic compares actual waste parameters and operating limits (lower left corner) to calculated subcritical concentration limits as identified by the two curves. The two subcritical concentration curves show the degree of conservatism that has been included in the criticality safety analysis of the Hanford Site tank wastes. The "optimized conservative waste model (CWM)" subcritical concentration represents conservatively modeled waste conditions as noted throughout this report. The "average waste composition" represents subcritical concentrations for a waste composition representing an average composition of 19 elements from 28 tank samples. All cases are calculated using additional conservatism (e.g., assumes a sphere geometry). Figure ES-1 shows that even with a high degree of conservatism, the waste tank contents are highly subcritical. 
WHC-SD-WM-TI -725

Revision 0

Figure ES-1. Plutonium Mass versus Concentration--Perspective of Hanford Site Waste Tank Subcritical Concentrations (Spherical Geometry).

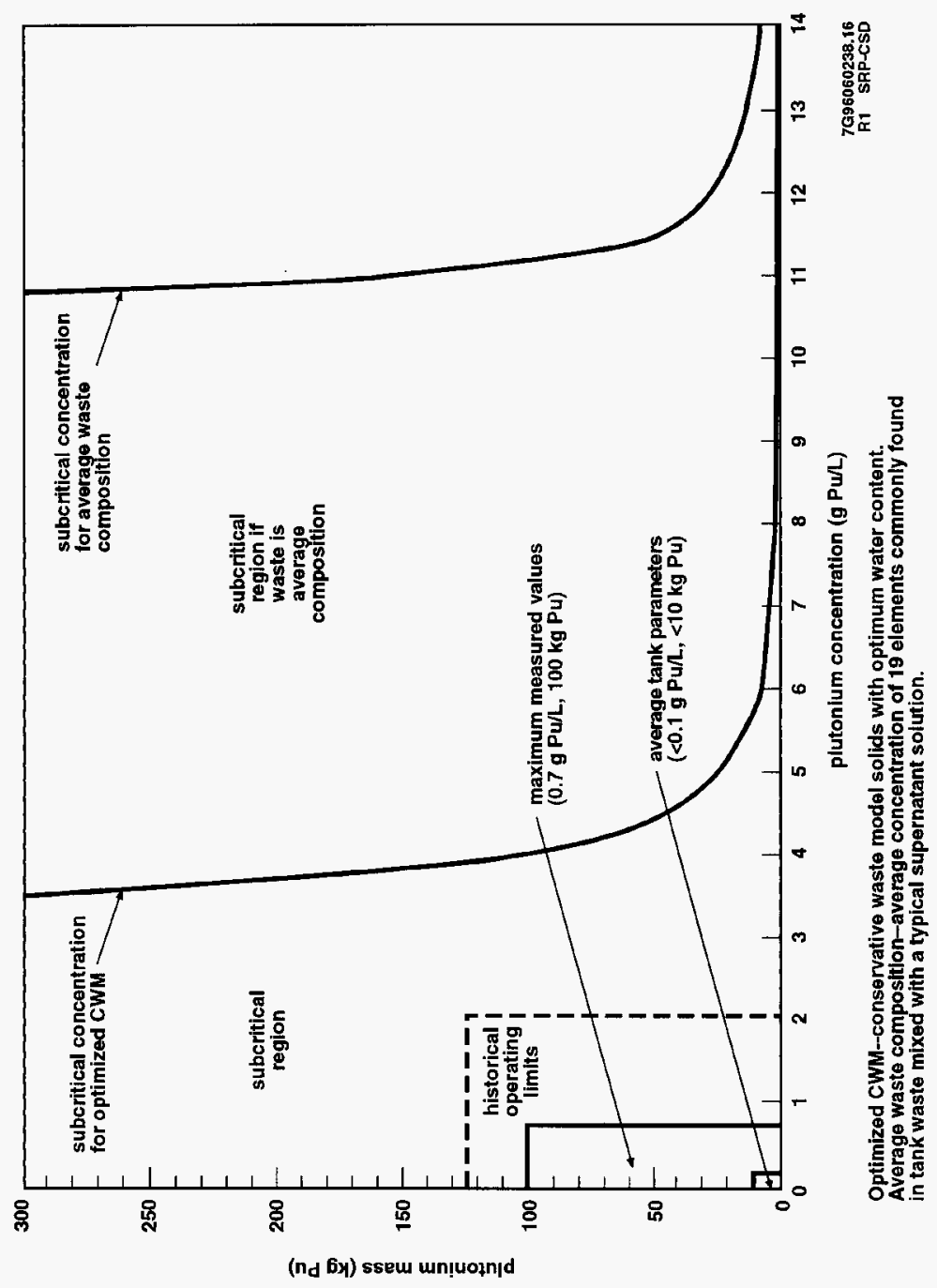

ES-3 
Abundant analytical data show that plutonium in SST and DST sludges is intimately associated with large amounts of iron, manganese, chromium, and other metals that are good neutron absorbers. These metals precipitated along with plutonium when initially acidic wastes were made alkaline before being introduced into the waste tanks. The neutron absorber(s)-to-plutonium mass ratios are typically well above those needed to ensure subcritical conditions. Washing and dissolution tests with representative sludges confirm that it is very difficult to separate plutonium from associated iron and other sludge constituents.

Water (i.e., hydrogen atoms) moderates neutrons, reducing their energy to thermal levels. Water also serves as a neutron absorber when in excess of some amount (optimum moderation). The stored tank wastes are, in general, over-moderated, which adds to the conservatism of the $2.6 \mathrm{~g} \mathrm{Pu} / \mathrm{L}$ minimum subcritical concentration criterion specifically derived for the Hanford Site waste tanks.

Although the most likely configuration of the solid waste form (which contains the majority of the fissile material) in the Hanford Site storage tanks is a slab-like layer, the waste form can also exist as other shapes (e.g., conical) from the waste addition process. At a concentration greater than $2.6 \mathrm{~g} \mathrm{Pu} / \mathrm{L}$, well above the maximum observed waste concentration, a slab can be made critical. However, large amounts and higher concentrations of plutonium (e.g., 5,000 $\mathrm{kg}$ at $3 \mathrm{~g} \mathrm{Pu} / \mathrm{L}, 1,500 \mathrm{~kg}$ at $6 \mathrm{~g} \mathrm{Pu} / \mathrm{L}$ ) would be required to attain criticality, and these are not achievable under current waste storage conditions. Regardless of the shape of the waste form, safety analysis calculations typically assume a sphere geometry (the most 
conservative shape from a neutronics perspective) to ensure they sufficientiy bound actual waste tank conditions.

Three potential chemical mechanisms whereby plutonium entered the sludge phase have been identified:

- Sorption onto precipitated hydrated metal oxide sludge particles

- Precipitation as pure plutonium oxide crystals

- Formation of solid-solid solutions with non-neutron absorbers such as $\operatorname{Zr}(\mathrm{IV})$.

If sorption were the dominant chemical mechanism, bonding of plutonium to strong neutron-absorbing metals such as iron and manganese ensures subcritical conditions. If pure hydrous plutonium oxide formed as a crystalline precipitate when acidic wastes were made alkaline, the plutonium oxide particles would be expected to agglomerate or mix with neutron absorbers. For nuclear criticality to occur for either of the latter cases, large (tens of micrometers in size) plutonium particles free of neutron absorbers must be created and then concentrated by some mechanism. All literature data, as well as calculations performed for modeling operational mechanisms such as salt well pumping, air lift circulators, and transfer pumps, indicate that creation and separation of such plutonium-bearing particles are not plausible. 
Finally, because ionic radii of $\mathrm{Pu}(\mathrm{IV}), \operatorname{Zr}(\mathrm{IV}), \mathrm{La}(\mathrm{III})$, and $\mathrm{Bi}(\mathrm{III})$ are quite similar, it is possible that some solid solution formation occurred in wastes containing these ions (e.g., zircaloy-cladding waste and bismuth process waste). However, the bismuth process waste solutions al so contained large quantities of $\mathrm{Fe}$ (III) so that in addition to possible solid solution with $B$ (III) and/or La(III), some of the plutonium could have co-precipitated with hydrated iron oxide. Also, in the zircaloy-cladding wastes, the zirconium-to-plutonium mass ratios exceeded the minimum ratio needed to ensure subcriticality.

In summary:

- Fissile material in the waste tanks is distributed at subcritical concentrations.

- No physical or chemical phenomena or mechanism has been identified that could concentrate fissile material at sufficient quantities or concentrations to result in an accidental nuclear criticality. 
WHC-SD-WM-TI-725

Revision 0

\section{ACKNOWLEDGEMENTS}

The technical analysis described in this report is based on an integrated, multidisciplinary approach by an extensive list of contributors. The Pacific Northwest National Laboratory (PNNL) provided the technical lead role for the evaluation of the physical and chemical phenomena, mechanistics, and modeling. In addition to R. J. Serne, the primary contributing author from PNNL, other PNNL contributors were P. G. Doctor, S. V. Mattigod, G. A. Whyatt, Y. Onishi, B. N. Bjornstad, L. M. Liljegren, N. J. Aimo, G. R. Golcar, T. B. Miley, G. R. Holdren, K. P. Recknagle, M. R. Powell, and J. H. Westsik. Westinghouse Hanford Company (WHC) contributors were D.W. Jeppson, R. K. Biyani, and G. S. Barney. C. G. Delegard of WHC contributed greatly to understanding the behavior of fissile materials in the Hanford Site waste storage tanks. In addition to the listed authors who contributed to the evaluation of the criticality physics, additional contributors included S. A. Parra and H. Harris of WHC. The authors also acknowledge the contribution of R. A. Werderman and P. L. Lintho who typed and prepared the report. 
WHC-SD-WM-TI-725

Revision 0

This page intentionally left blank. 
WHC-SD-WM-TI-725

Revision 0

\section{CONTENTS}

1.0 INTRODUCTION . . . . . . . . . . . . . . . . . . 1-1

1.1 OBJECTIVE . . . . . . . . . . . . . . . . . . . . 1-1

1.2 REPORT SCOPE ...................... . . . . . .

1.3 BACKGROUND . . . . . . . . . . . . . . . 1-1

1.4 NUCLEAR CRITICALITY SAFETY ISSUE BACKGROUND . . . . . . . 1-4

1.5 TECHNICAL APPROACH . . . . . . . . . . . . . . 1-6

2.0 WASTE TANK CRITICALITY ............... . . 2-1

2.1 FISSILE MATERIAL CONCENTRATION . . . . . . . . . . 2-1

2.2 OTHER NUCLEAR CRITICALITY FACTORS .......... 2-3

2.2.1 Neutron Absorbers . . . . . . . . . . . 2-3

2.2.2 Neutron Moderation . . . . . . . . . 2-5

2.2.3 Areal Concentration Limit . . . . . . . . 2-5

2.2 .4 Geometry. . . . . . . . . . . . 2-6

2.2.5 Minimum Critical Mass . . . . . . . . . . 2-6

2.3 PERSPECTIVE ON PLUTONIUM CONCENTRATION WITHIN TANK WASTE FORMS 2-7

2.4 CRITICALITY PERSPECTIVES FOR WASTE HETEROGENEITY . . . . . . . 2-9

3.0 WASTE TANK HISTORY WITH RESPECT TO CRITICALITY HAZARD . . . . . 3-1

3.1 WASTE TO TANKS ................. . . . .

3.1.1 Physical Considerations . . . . . . . . . 3-1

3.1.2 Chemical Considerations .......... . . . 3-5

3.2 WASTE TANK CHARACTERIZATION ANALYSES ......... 3-9

3.3 WASTES STORED WITHIN THE TANKS AND THE WASTE AGING PROCESS . . 3-10

3.3 .1 Sludge . . . . . . . . . . . . . 3-10

3.3.2 Supernatant Liquid . . . . . . . . . . . . 3-12

3.3.3 Salt Cake . . . . . . . . . . . . . . . . . 3-14

3.4 PLUTONIUM CONCENTRATION MECHANISMS . . . . . . . . . . . . 3-14

3.4.1 Physical Considerations . . . . . . . . . . . . . 3-15

3.4.2 Chemical Considerations . . . . . . . . . . 3-17

4.0 CONCLUSIONS . . . . . . . . . . . . . . . 4-1

5.0 REFERENCES . . . . . . . . . . . . . . . . 5-1

\section{APPENDIXES}

A PLUTONIUM INVENTORY FOR HANFORD SITE SINGLE-SHELL TANKS . . . . . A A-1

B PLUTONIUM INVENTORY FOR HANFORD SITE DOUBLE-SHELL TANKS . . . . . . B- 1 
WHC-SD-WM-TI-725

Revision 0

\section{LIST OF FIGURES}

1-1 Typical Double-She11 Tank Waste Configuration. . . . . . . . . . . 1-3

1-2 Typical Stabilized Single-Shell Tank Waste Configuration . . . . . 1-3

2-1 Plutonium Concentration Factor versus Minimum Critical Sphere

Diameter. . . . . . . . . . . . . . . . . 2-2

2-2 Plutonium Concentration versus Mass Contained in a Critical Slab in a 22.9-m-Diameter Tank. . . . . . . . . . . . . . . . 2-7

3-1 Excess Neutron Absorber Content in Waste Streams Based on Flowsheet Composition ........................ . . . 3-4

3-2 Chemical and Physical Considerations Related to Tank Criticality. . 3-7

3-3 Model Sorption and Desorption Isotherms for Plutonium Sorption on Metal Oxyhydroxides. . . . . . . . . . . . . . 3-20

3-4 Plutonium Oxyhydroxide Solubilities Compared with Measured Plutonium Concentrations in Double-She11 Tank Supernate Solutions for Various Carbonate Concentrations. . . . . . . . . . . . . 3-20

\section{LIST OF TABLES}

2-1 Insoluble Absorber-to-Plutonium Minimum Subcritical Ratios . . . . 2-3

2-2 Soluble Absorber-to-Plutonium Minimum Subcritical Ratios . . . . . 2-4

3-1 Mass Ratios in Selected Waste Streams Sent to the Tank Farms. . . . 3-3

3-2 Typical Mass Ratios in Waste Tanks. . . . . . . . . . . . . . 3-5

3-3 Comparison of Plutonium, Iron, and Aluminum Hydroxide Solubilities. 3-9 
WHC-SD-WM-TI-725

Revision 0

\section{TANK FARM NUCLEAR CRITICALITY REVIEW}

\subsection{INTRODUCTION}

\subsection{OBJECTIVE}

The purpose of this report is to evaluate the possibility of chemical and/or physical phenomena and mechanisms by which the fissile components of the stored waste at the Hanford Site could become separated from the associated waste solids and form an area where the fissile material concentration, volume, and geometry are favorable to result in an accidental criticality.

This analysis provides the technical basis for the Final Safety Analysis Report (FSAR) hazard and accident analysis. This report also provides the technical basis required to resolve the nuclear criticality safety issue technical concerns regarding the evaluation of postulated mechanisms that may result in the redistribution of fissile material in the waste form.

\subsection{REPORT SCOPE}

The scope of this report includes a technical analysis of historical data with respect to past operations and the existing waste tank contents, waste partitioning and distribution phenomena, mechanisms, and neutronics to support the FSAR as well as to resolve the nuclear criticality safety issue. Specifically, this report provides the requisite technical analysis to support the FSAR hazard and accident analysis as well as to determine the required limits and controls to ensure the waste remains subcritical under present waste storage activities.

The scope of this technical basis report provides a baseline for understanding the chemical and physical phenomena and mechanisms in relationship to operational activities defined within the scope of the FSAR (i.e., "safe storage"). Operational facilities affected by this technical analysis include single-shell tanks (SST), double-shell tanks (DST), and double-contained receiver tanks (DCRT). Although the FSAR does not include future operational activities (retrieval or pretreatment), this report provides a sound technical basis to support independent safety analyses for future activities. Many of the same mechanisms relating to safe storage of the waste also relate to future retrieval activities (e.g., waste transfer and mixer pump operations).

\subsection{BACKGROUND}

During its operating life, the Hanford Site has generated a significant quantity of waste material, including the fissile isotopes of plutonium and uranium. Because the mission of the Hanford Site was to maximize plutonium output for defense purposes, there was a strong incentive to minimize the amount of this material discarded as waste. The best estimate for the total 
amount of plutonium that entered the Hanford Site waste tanks is about $500 \mathrm{~kg}$. Given the uncertainties in some measurements, some estimates are as high as $1,000 \mathrm{~kg}$ (Roetman et al. 1994).

Wastes at the Hanford Site have been stored in large underground storage tanks. A technical guide to understanding the Hanford Site chemical reprocessing mission leading to the production of radioactive wastes and waste management operations can be found in Gephart and Lundgren (1995). Of the 177 waste tanks on the Site, 149 are SSTs that have no current waste transfer activity, and 28 are the newer (DSTs). Figure 1-1 illustrates a typical waste form inventory within the DSTs (unstabilized, because waste transfers are fairly recent), and Figure 1-2 illustrates the waste form for the SSTs. In both cases, salt cake was formed from the crystallization of chemicals after the supernatant liquid was evaporated during volume reduction operations. Sludge, a thick layer containing chemicals that have precipitated from solution, forms the bottom layer in all the tanks.

Waste management practices at the Hanford Site always required that liquid waste streams generated in production plants be neutralized with sodium hydroxide before transfer to the low-carbon steel underground tanks. Addition of sodium hydroxide not only precipitated fissile materials in the waste but also co-precipitated various nonradioactive metal cations such as iron and other effective neutron absorbers. All fuel reprocessing and product purification plants either used large amounts of iron-containing reagents or added them during sodium hydroxide neutralization operations. The fine particulate solids that precipitated from the alkaline solution settled slowly in the waste tank to typically form slab-like waste layers (other waste form shapes can occur as we11, however).

The waste streams entered the storage tanks either on the side of the tank or through a dome penetration. The waste stream containing the flocculated solids flowed into the tank and dispersed into an approximately flat layer. Dome entry allowed the waste stream to free fall $3.1 \mathrm{~m}$ or more before striking the tank liquid layer. This free fall enhanced the dispersion of the waste stream, permitting a more uniform horizontal solids cake (sludge layer) in the tank.

To increase the storage capacity of the tanks, dilute waste supernatant solutions, containing water-soluble salts produced by acid neutralization, were heated to remove water. Two methods used were in-tank solidification and successive-pass external evaporation, which returned the concentrated waste to the tanks. The results were the same in both cases. Large quantities of water were removed, the solubility of the salts contained in the wastes was exceeded, and the salts crystallized and settled out in the tanks, usually resulting in a five to tenfold reduction in volume. The salts that settled in the tanks became "salt cake," which formed a layer on top of existing sludge inventories. One result of such evaporative processing was the concentration of sodium hydroxide and aqueous soluble organic complexants in the waste, most of which remained in solution. 
WHC-SD-WM-TI-725

Revision 0

Figure 1-1. Typical Double-She11 Tank Waste Configuration.

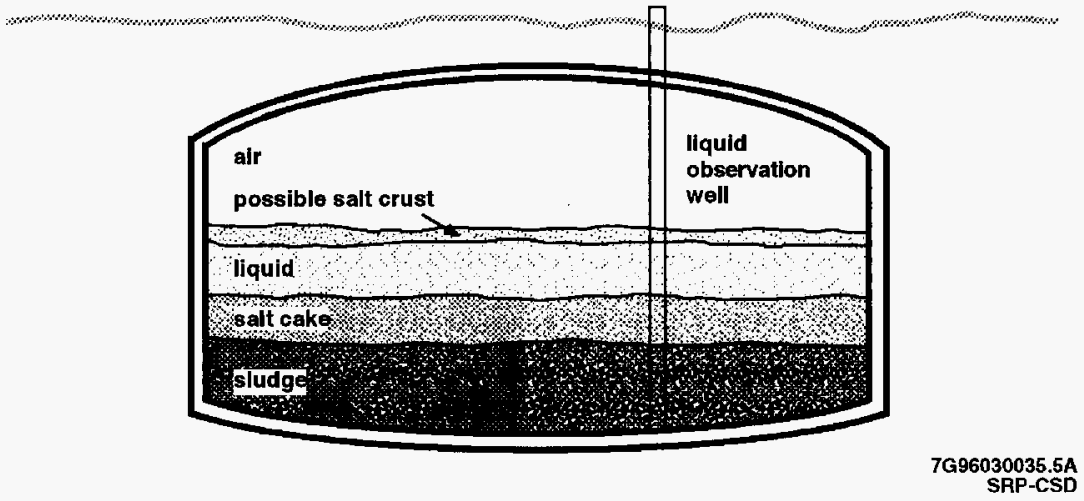

Figure 1-2. Typical Stabilized Single-Shell Tank Waste Configuration (After Salt Well Pumping).

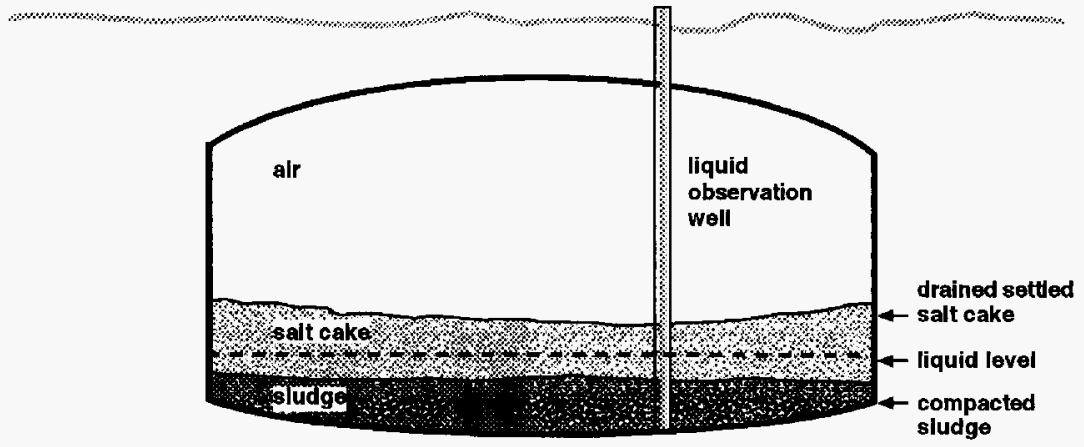

7G96030035.5B

SRP-CSD 
WHC-SD-WM-TI-725

Revision 0

As part of an effort to reduce the potential for leakage of fluid from SSTs, the tanks were salt-well pumped and most of the drainable liquids were transferred to DSTs. This further compacted the sludge and salt cake layers. The resulting waste contained considerable amounts of non-drainable 1iquids, a)though some drainable wastes remained.

Historically, the concentration of the fissile material in the tank wastes has been controlled at a level that would make the initiation of a self-sustaining nuclear chain reaction (a criticality accident) incredible. The belief that a criticality accident is incredible has been based on the assumption that the fissile components of the waste remain at a relatively low concentration and are relatively well mixed with the large amount of oxyhydroxide solids (i.e., neutron absorbers) that were, in general, transferred along with the fissile materials (Braun et al. 1994).

\subsection{NUCLEAR CRITICALITY SAFETY ISSUE BACKGROUND}

An Unusual 0ccurrence Report involving nuclear criticality safety in the Hanford Site high-level radioactive waste tank 241-C-104 was filed in June 1991. An analysis of a single core sample indicated the tank might have a calculated total tank fissile material value greater than the criticality prevention specification limit of $125 \mathrm{~kg}$. A Westinghouse Hanford Company (WHC) investigation team was formed in accordance with procedures, and the team established a plan of recovery from the noncompliance. The team discovered an error in the laboratory analysis and determined that the fissile material content was well within the criticality prevention specification limit. However, the investigation team continued to assess the overall criticality safety program in the tank farms.

As a result of the tank 24l-C-104 activities, the U.S. Department of Energy (DOE) supported a review by nationally recognized criticality safety experts. The DOE team reviewed the Tank Farm Criticality Safety Program in November 1991 and reported its findings in January 1992. The DOE review team concluded, in part, that the WHC investigation was thorough and the recommendations were good, and that there was no imminent risk of a criticality at the Hanford Site tank farms. The primary concerns of the DOE review team were the lack of definitive knowledge of the fissile material inventory and distribution within the tanks and the lack of WHC management support for the overall criticality safety program.

Subsequently, a briefing of the Defense Nuclear Facilities Safety Board generated questions regarding the effectiveness of administrative controls to keep track of the fissile material content in the tanks. A fissile material inventory system was subsequently developed and has been actively maintained (Tusler 1995).

On April 30, 1992, a plant review committee reviewed the safety analysis reports for the SSTS, DSTs, and aging waste tanks in 1 ight of the conclusion that waste characterization was inadequate with respect to fissile material content. The review indicated that the conclusion in the safety analysis, which stated that a criticality is "not credible," was not supported for a ful1 range of postulated tank constituents. Therefore, an unreviewed safety question (USQ) was declared. 
After an extensive study of the limited available data, no credible criticality scenario could be supported. Also, based on the study of process data from the waste-generating facilities during past years, waste chemistry, and the samples of available waste, it was determined that the waste in the tanks was subcritical by a large margin (Braun et a1. 1994). This assessment applied to continued storage, and also provided guidance for future tank farm-allowed operations.

After extensive review, the Assistant Secretary for Environmental Restoration and Waste Management approved closure of the USQ in March 1994. The letter also indicated that a safety issue remained.

The safety issue is defined as follows in Antizzo (1995):

". . the lack of definitive knowledge of the fissile and absorber material inventory and distribution in the high-level waste (HLW) tanks. The HLW tanks include Double Shell Tanks (DSTs), Single Shel1 Tanks (SSTs), Doubly Contained Receiver Tanks (DCRTs), and Catch Tanks." . . While the USQ closure provided a high degree of confidence in the present subcriticality of the Hanford tanks, it could not resolve the central cause of the safety issue: uncertainties in the fissile and absorber materials inventories and distributions in the tanks which could conceivably affect the safety of present, as well as future, operations."

In addition, Hanford Federal Facility Agreement and Consent Order (Tri-Party Agreement) (Ecology et a1. 1996) Milestone M-40-12 was defined as "Resolve Nuclear Criticality Safety Issue" (due September 1999).

The evaluation and conclusions established in the present technical basis report provide considerable advancement of the "definitive knowledge" of the fissile material and absorber content of the waste being stored in the Hanford Site tanks. The evaluation of data related to the chemical separations facilities and subsequent waste stream compositions confirm previous baseline plutonium inventory calculations (Serne et a7. 1996).

By definition of the safety issue, obtaining additional empirical data (i.e., waste tank characterization) has been implied to provide more definitive knowledge of the fissile and absorber material inventory and distribution. Although additional tank waste characterization and analysis of the tank waste inventory and distribution has been performed (Serne et al. 1996), evolution of the Hanford Site Safety and Characterization Programs has demonstrated that focusing on gaining detailed empirical data of the waste tank contents (i.e., extensive characterization) is neither technically practical nor cost-effective to fully resolve waste tank safety issues. The strategy presented in the present technical basis report has been recommended by an expert criticality review team and is a more technically comprehensive and defensible approach. This approach evaluates the chemical and physical phenomena and mechanisms to ensure present waste storage conditions do not affect the form and distribution of fissile or neutron absorber material to the extent that the tanks can no longer be ensured to remain subcritical. 
WHC-SD-WM-TI-725

Revision 0

\subsection{TECHNICAL APPROACH}

Section 2.0 provides an overview of the neutronics of the waste with respect to the criticality safety issue. Many parameters (e.g., concentration of fissile material, presence of neutron-moderating materials, presence of neutron absorbers, geometry, and areal density) can be used to support the subcritical operation of the waste storage operations. Of these parameters, fissile material (i.e.s plutonium) concentration is the single most important parameter and it has been relied on during the history of the waste storage operations. Records and procedures existing from the mid-1960's required control of the concentration of fissile material in the discharged waste streams at a level that would ensure subcriticality. (Procedures and criticality safety analysis records from before the mid-1960's have not been found, but a study of flowsheets and waste transfer records indicates that concentration controls have always been in effect.) The large number of waste sample analyses (more than 500 samples), although not defensible as being totally representative of the entire population of waste, is within the identified concentration 1 imits and strongly supports the effectiveness of these concentration controls.

In addition to concentration, the other noted criticality parameters (e.g., areal density, neutron moderation, total neutron absorber content, and geometry) add an additional margin of safety to ensure the waste remains subcritical.

Plutonium solubility and characterization data (Braun et al. 1994) show that sufficient plutonium concentrations or mass cannot exist in the liquid (supernate) and salt cake layers to present a criticality risk. Thus, the bulk of the plutonium is in the solid (sludge) phase of the waste form. The fissile material is associated with oxyhydroxide solids in the sludge phase that provide neutron absorption capability to ensure the waste remains subcritical. This sludge has been conservatively modeled (Rogers 1996); the modeling results have been used to calculate conservative subcritical fimits for stored waste.

An assumption in previous criticality technical basis documentation relating to the Hanford Site tanks (Braun et al. 1994) is that the fissile and neutron absorber (solids) components of the waste materials are well mixed and approximate a homogenous system. An extensive analysis has been subsequently performed to investigate and understand the chemical and/or physical phenomena and mechanisms that could result in the segregation/concentration of fissile material to the extent that the continued subcriticality could not be ensured. Section 3.0 provides an overview of the analysis results. In conclusion, no credible segregation/concentration mechanisms have been identified that are capable of separation/concentration factors of a magnitude that could result in a significant reduction in the current degree of subcriticality (Serne et a1. 1996). 
WHC-SD-WM-TI-725

Revision 0

\subsection{WASTE TANK CRITICALITY}

Waste tank nuclear criticality is a function of the following four factors:

- Fissile material concentration
- Neutron absorbers
- Geutron moderation
Geometry.

Fissile material consists of the odd-numbered isotopes of uranium and plutonium. The fissile material content of the waste is expressed in terms of its ${ }^{239} \mathrm{Pu}$ equivalence. Consequently, all i sotopes of plutonium (i.e., ${ }^{238} \mathrm{Pu}$, ${ }^{239} \mathrm{Pu},{ }^{240} \mathrm{Pu}$, and ${ }^{241} \mathrm{Pu}$ ) are conservatively treated as ${ }^{239} \mathrm{Pu}$. In addition, the ${ }^{233} U$ and ${ }^{235} U$ inventories are added to the plutonium inventory. The ${ }^{235} U$ in natural and depleted uranium is prohibited from criticality by the presence of a large ratio of ${ }^{238} \mathrm{U}$ and is not included in the inventory.

The following discussion of parameters that affect the reactivity of stored waste is based on two key assumptions.

- All calculations are for systems at optimum moderation (this means that the hydrogen [water] content for all systems is assumed to be at a level that results in the lowest possible critical mass for the system being discussed). Addition or subtraction of water from an optimaliy moderated system results in a decrease in reactivity and an increased margin of safety (see Section 2.2.2 for further discussion).

- The non-fissile waste materials have a neutron absorption capacity equal to that of the conservative waste model (CWM) (Rogers 1993 and 1996), a model of the neutron absorption properties of the waste (see Section 2.1 for further discussion).

\subsection{FISSILE MATERIAL CONCENTRATION}

For the Hanford Site tank waste, the plutonium concentration must be at least $2.6 \mathrm{~g} \mathrm{Pu} / \mathrm{L}$ before criticality becomes possible, even in an unlimited volume of waste. This value is based on a uniform mixture of plutonium, waste solids, and water. The CWM and waste solids composition are described in WHC-SD-SQA-SA-20356 (Rogers 1996). This CWM defines the waste composition by using the maximum reported value for solids materials that are good neutron reflectors and the minimum reported values for solids materials that are good neutron absorbers. The CWM also assumes the water content is optimized. Note that the use of this CWM results in a minimum subcritical plutonium concentration value that is well below the value of $7.2 \mathrm{~g} / \mathrm{L}$, which is generally reported as the minimum critical concentration of plutonium in water.

Plutonium concentration has historically been used as the primary control on waste streams discharged to the storage tanks (Serne et a1. 1996). Documents and procedures from the mid-1960's indicate control of discharge 
levels at a maximum of $0.013 \mathrm{~g} \mathrm{Pu} / \mathrm{L}$ in a waste mixture being routed to a waste tank and $1 \mathrm{~g} \mathrm{Pu} / \mathrm{L}$ in waste tank solids (Braun et a1. 1994). Reviews of flowsheets and waste transfer documents produced before 1960 indicate that this level of control has always existed. A statistical analys is of the extensive number of waste tank characterization samples to date (more than 500) confirms the effectiveness of the concentration controls (Serne et al. 1996).

In addition to the discussion of the minimum critical concentration, it is important to understand the concentration factor that would be required to increase the present concentration of plutonium in waste to a level at which subcriticality could no longer be ensured.

Figure 2-1 is based on a theoretical tank inventory of $100 \mathrm{~kg} \mathrm{Pu}$ that is uniformly distributed throughout the contents of a tank that is one-half full. This results in a nominal concentration of $0.05 \mathrm{~g} \mathrm{Pu} / \mathrm{L}$. A concentration factor of $80(4 \mathrm{~g} \mathrm{Pu} / \mathrm{L})$ is required before criticality could be achieved, and then only if the material is configured in a sphere approximately $3.7 \mathrm{~m}$ in diameter. A concentration factor of 100 (i.e., $5 \mathrm{~g} \mathrm{Pu} / \mathrm{L}$ ) requires that the material be configured in a $2.1-\mathrm{m}-\mathrm{diameter}$ sphere.

Figure 2-1. Plutonium Concentration Factor versus Minimum Critical Sphere Diameter.

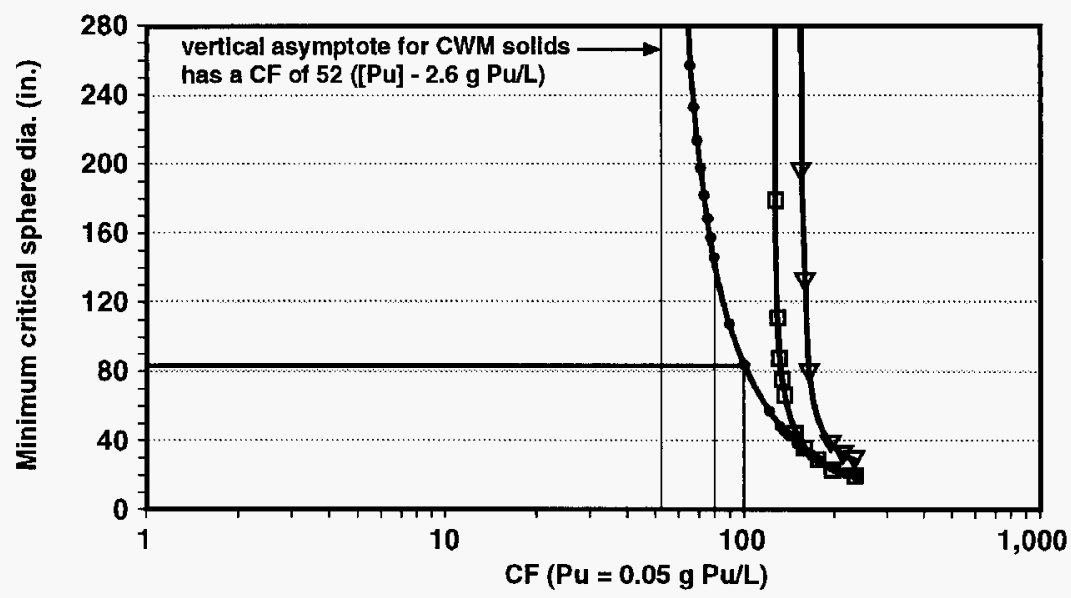

$\rightarrow$ CWM sollds $\square$ pure water $\rightarrow$ supernate

CF = concentration factor

CWM $=$ conservative waste model 
If this example is applied to tank 241-C-106 (total estimated plutonium inventory of $100 \mathrm{~kg}$ at a concentration of $0.132 \mathrm{~g} \mathrm{Pu} / \mathrm{L}$ and a sludge depth of approximately $1.8 \mathrm{~m}$ ), a concentration factor of approximately 40 is needed to form a critical sphere that will fit within the thickness of the existing sludge layer. This perspective indicates that even under the most conservative conditions, significant concentration factors would be required to approach a critical system and the resulting critical sphere would need to be as large as, or larger than, the thickness of the solids layer. Note that spheres are calculated in this case for conservatism. More realistic slab-like layers would require considerably higher plutonium concentrations before subcriticality could no longer be ensured.

\subsection{OTHER NUCLEAR CRITICALITY FACTORS}

The technical analysis provided thus far provides a bounding case to ensure tank waste will remain subcritical based on insufficient concentration of the fissile material in the presence of conservatively modeled solids. There are, however, many other factors that provide an additional margin of subcriticality. The variability in tank-to-tank composition, the difficulty in obtaining representative tank samples, and the lack of historical operational control make it impractical to take quantitative credit for these factors. They do, however, contribute qualitatively to the overall safety basis. The following assessment provides justification for an increased level of confidence in the continued subcritical operation based on factors other than concentration.

\subsubsection{Neutron Absorbers}

Neutron absorbers reduce the reactivity of any fissile mixture. There is a unique minimum absorber-to-plutonium mass ratio (X/Pu) for all absorbers, above which the system will remain subcritical, independent of any other influences. This mass ratio is calculated for a mixture of plutonium, absorber, and water and is applicable when the waste is relatively homogeneous. Because waste was sent to the tank farms as a relatively homogenized mixture, the absorber-to-piutonium ratio is a good indicator of subcriticality. Minimum subcritical absorber-to-plutonium ratios have been calculated for the more important elements in sludges. The results are reported in Tables 2-1 and 2-2.

Table 2-1. Insoluble Absorber-to-Plutonium Minimum Subcritica1 Ratios (S1udge).

\begin{tabular}{|l|c|}
\hline \multicolumn{1}{|c|}{ Element } & $\begin{array}{c}\text { Minimum subcritical ratio } \\
(X / \text { Pu mass ratio) }\end{array}$ \\
\hline Chromium & 135 \\
\hline Iron & 160 \\
\hline Manganese & 32 \\
\hline Nicke 1 & 105 \\
\hline Uranium (natural) & 770 \\
\hline
\end{tabular}


Table 2-2. Soluble Absorber-to-Plutonium Minimum Subcritical Ratios (Salt Cake or Liquid).

\begin{tabular}{|l|c|}
\hline \multicolumn{1}{|c|}{ Element } & $\begin{array}{c}\text { Minimum subcritical ratio } \\
(X / \text { Pu mass ratio })\end{array}$ \\
\hline Aluminum & 910 \\
\hline Nitrate & 270 \\
\hline Sodium & 360 \\
\hline
\end{tabular}

The relative contribution of a component to the subcriticality of a system can be found by dividing its actual mass ratio by the corresponding subcritical mass ratio. This ratio of mass ratios is referred to as the absorber fraction. An absorber fraction greater than 1.0 means that a uniform mixture will be subcritical. Waste is composed of many different components, each with its own minimum absorber-to-plutonium subcritical ratio. The combined effect of these absorbers can be estimated by summing individual absorber fractions according to the formula:

$$
\begin{aligned}
& \text { If } \sum_{j=1}^{N} \frac{\left(\frac{X_{j}}{P u}\right)_{\text {actual }}}{\left(\frac{X_{j}}{P u}\right)_{\text {suberitical }}} \geq 1 \\
& \text { then } k_{\infty} \leq 1
\end{aligned}
$$

The High-Level Waste Subcriticality Safety Assessment document (Braun et al. 1994) contains a review of 463 analyzed solid and liquid samples taken from tank waste. Of these, the reported results for 413 samples showed sufficient quantities of selected components to demonstrate subcriticality independent of any other controls. The other samples had sufficient absorber content to provide substantial neutron absorbtion, but not sufficient to render the sample subcritical by neutron absorbers alone. Note, however, that some samples were not analyzed for all components of interest from a criticality safety perspective. These samples were not chemically analyzed to demonstrate subcriticality and may not, therefore, provide an accurate accounting of components of interest to this evaluation. A rigorous review of the data was conducted for use in criticality safety evaluations and noted sample analysis results from five samples were eliminated as erroneous data. Elimination of the sample results is based on (1) recognized analytical laboratory errors, or (2) use of sample preparation procedures for specific process needs which rendered the results inapplicable for fissile material inventory purposes (i.e., nonrepresentative of actual tank waste conditions). Section 3.1.1 provides additional analysis of the margin of subcriticality based on the neutron absorber content of the waste stream and waste tank contents.

Two of the most effective absorber materials (boron and cadmium) have been excluded from the CWM. They have been excluded because their 
WHC-SD-WM-TI-725

Revision 0

concentration and distribution in the waste form cannot be ensured for a11 waste streams (nor are the waste samples routinely analyzed for these elements). However, some waste streams are known to have substantial quantities of these excellent neutron absorbers in the waste solids. They are such strong absorbers that their contribution would totally dominate the CWM and the discussion would immediately center on defending the uniformity of their distribution. Therefore, they have been purposely exciuded to better defend the conservatism of the CWM.

\subsubsection{Neutron Moderation}

Minimum critical mass is achieved by optimum moderation and infinite reflection. There is a certain amount of hydrogen (e.g., water) that achieves optimal moderation. In this case, the energy of a fast neutron is reduced to a thermal neutron by loss of energy through collision with hydrogen. The neutron energy is reduced such that the ratio of the absorption-to-fission cross section is minimized. In an over-moderated system, additional water does little to further thermalize the neutron spectrum, but introduces additional neutron absorption thereby reducing the reactivity of the system. If the system is calculated for optimum moderation, any change in hydrogen content will result in a less reactive system. Note that moderation is not related to an absolute quantity of plutonium and water, but to the ratio of hydrogen atoms to plutonium atoms.

Water is the principal source of hydrogen and thus the principal moderator in the Hanford Site tank wastes. Generally, the waste form is over-moderated. This results in higher minimum critical plutonium concentrations than those identified in Section 2.1. Sludge and supernate liquid are grossly over-moderated, while salt cake may be near optimal moderation (Rogers 1996). The range of water content in most tank layers is as follows:

- Liquid: $65 \%$ to $95 \%$ water

- Sludge: $20 \%$ to $80 \%$ water (in some cases may be as $10 w$ as $5 \%$ )

- Salt cake: $5 \%$ to $65 \%$ water.

The plutonium content of salt cake and liquid supernatants is low. Over-moderation in sludge results in an enhanced absorber effect (i.e., the macroscopic absorption cross sections are higher at the low neutron energy that results from an abundance of water moderation), thereby increasing the subcritical margin of safety.

\subsubsection{Areal Concentration Limit}

Carter et al. (1970) calculated that the minimum critical areal density for plutonium in pure water is $2,580 \mathrm{~g} / \mathrm{m}^{2}$. The assumption of water as a neutron reflector is a conservative position in the case of areal density because the reactivity is driven by leakage rather than by neutron absorption. The actual distribution of plutonium in the waste does not matter. As long as the plutonium content above any square meter of floor area does not exceed $2,580 \mathrm{~g} \mathrm{Pu} / \mathrm{m}^{2}$, the waste will be subcritical independent of the actual distribution and moderator content. This remains true even if the plutonium 
concentration exceeds the minimum critical volumetric concentration 1 imits in localized regions and the water content is optimized. The areal concentration limit is particularly applicable to those tanks containing a measurable sludge 1ayer.

Actual tank waste contains neutron absorbers that result in a higher minimum critical plutonium areal density. As the plutonium concentration drops below $7 \mathrm{~g} \mathrm{Pu} / \mathrm{L}$, the minimum critical areal density increases rapidly. Below $2.6 \mathrm{~g} \mathrm{Pu} / \mathrm{L}$, the minimum critical areal density becomes infinite.

\subsubsection{Geometry}

Geometry plays a strong role in determining subcritical limits because of its impact on neutron leakage. Because of the immense size of the Hanford Site tanks, the geometry is normally considered to be essentially infinite, at least in the lateral direction (slab geometry). If the tanks can be shown to be subcritical for infinite conditions, any tank of finite size will be even more subcritical.

The effects of geometry are typically discussed in terms of a sphere. This is because a sphere is the most reactive geometry and thus constitutes the bounding case. For concentration factors in the range of $100: 1$, the critical sphere size is in the range of, or well beyond, the thickness of the solids layer in most tanks. From a practical perspective, it is impossible to visualize a credible mechanism by which fissile material can be configured into a sphere of this size. The most probable configuration of the waste form is an approximation of a slab although other waste form shapes are known to exist.

Figure 2-2 shows the relationship between plutonium concentration and minimum mass for a critical slab in a 22.9-m-diameter tank. As shown in Figure 2-2, a slab containing approximately $1,000 \mathrm{~kg}$ of plutonium would be subcritical for any concentration. Additionally, $5,000 \mathrm{~kg}$ of plutonium would be required at a concentration of $3 \mathrm{~g} \mathrm{Pu} / \mathrm{L}$, or $1,500 \mathrm{~kg}$ of plutonium would be required at a concentration of $6 \mathrm{~g} \mathrm{Pu} / \mathrm{L}$.

\subsubsection{Minimum Critical Mass}

The minimum critical mass of plutonium is $520 \mathrm{~g}$. Criticality is not possible with less than $520 \mathrm{~g}$ of plutonium regardless of other parameters. Consequently, for tanks containing less than $520 \mathrm{~g}$ of plutonium, there is no limiting critical concentration (i.e., they are inherently subcritical). However, the difficulties in obtaining an absolute quantitative plutonium inventory for individual tanks make it very difficult to defend the criticality safety of a tank based on inventory alone. 
Figure 2-2. Plutonium Concentration versus Mass Contained in a Critical Slab in a 22.9-m-Diameter Tank.
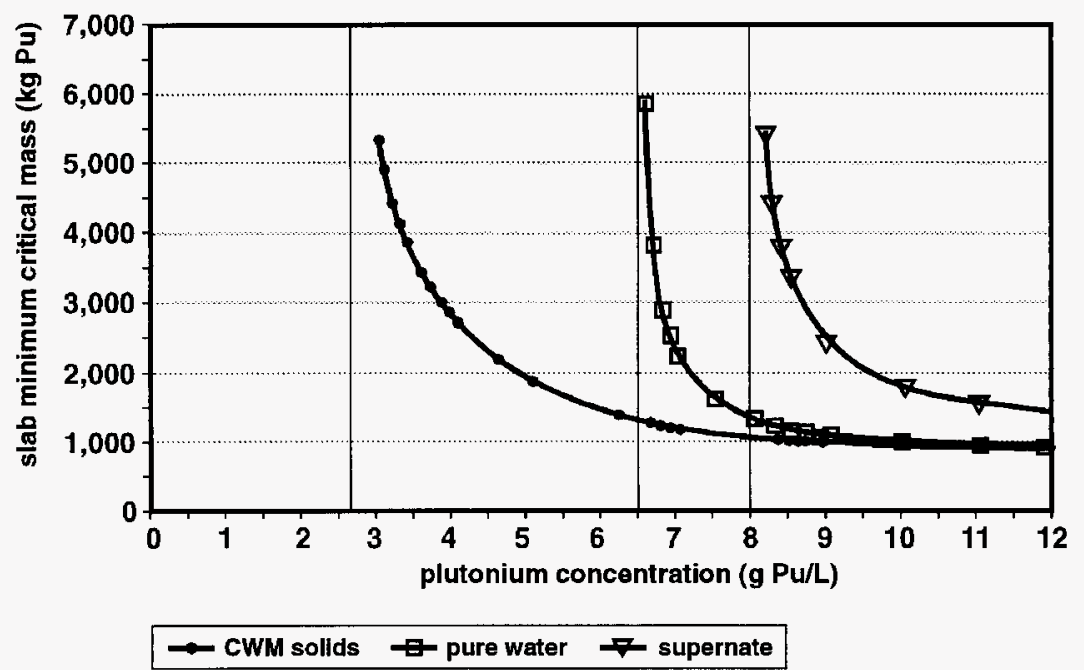

$$
\text { CWM = conservative waste model }
$$

\subsection{PERSPECTIVE ON PLUTONIUM CONCENTRATION WITHIN TANK WASTE FORMS}

Given the minimum volumetric subcritical concentration of $2.6 \mathrm{~g} \mathrm{Pu} / \mathrm{L}$, some perspective can be gained on the safe plutonium concentration in various regions of the tanks. For the liquid (supernatant) regions, the concentration of plutonium is intrinsically low, in the range of 0.0002 to $0.2 \mathrm{~g} \mathrm{Pu} / \mathrm{L}$. The solubility of plutonium is about $0.002 \mathrm{~g} \mathrm{Pu} / \mathrm{L}$ for solutions not containing materials that form complexes with plutonium at pH greater than 12 . The $0.2 \mathrm{~g}$ $\mathrm{Pu} / \mathrm{L}$ solubility value corresponds to a high carbonate solution at a $\mathrm{pH}$ equal to 9 , but this higher solubility limit is still less than $10 \%$ of the plutonium volumetric concentration limit identified above. Of the 308 liquid samples analyzed from the tanks, none contained more than $0.2 \mathrm{~g} \mathrm{Pu} / \mathrm{L}$.

The plutonium in the interstitial liquid in salt cake also has a solubility limit of $0.2 \mathrm{~g} \mathrm{Pu} / \mathrm{L}$. The crystalline portion of the salt cake is nominally free of plutonium because plutonium cannot enter the crystal structure due to its large ion radius. Although there could be some sludge entrained in the salt cake, the sludge quantities are relatively small and do not present a criticality risk. 
The bulk of the plutonium is in the sludge. Consequently, criticality concerns need to be addressed only in the sludge layer. Of the 216 solid samples analyzed to verify that they have met regulatory protocol requirements (Brevick 1995), al1 216 samples had less than $10 \%$ of the $2.6 \mathrm{~g} \mathrm{Pu} / \mathrm{L}$ minimum subcritical concentration criterion. Furthermore, plutonium is broadly distributed throughout the sludge from the initial waste stream neutralization process with a substantial excess of other metal oxyhydroxides. Additional discussion of the waste tank chemistry and physics is included in Section 3.0.

By using the plutonium concentration limits identified in Section 2.1, it is possible to assess potential criticality concerns in the Hanford Site waste tanks. Waste added to the tanks as suspended solids tended to settle slowly over the underlying waste surface. Thus, each waste layer appears to be relatively distributed in composition. Moving down the vertical profile in a tank, significant changes in waste composition (reflecting the different waste processes as a function of time) can be expected.

When the areal concentration criterion of $2,580 \mathrm{~g} \mathrm{Pu} / \mathrm{m}^{2}$ is applied over the full area of a 22.9-m-diameter tank, the resulting total load of $1,060 \mathrm{~kg}$ per tank would be subcritical. This value is about twice the best estimate of all the plutonium sent to the waste tanks, and it approximately equals the maximum estimate of $1,000 \mathrm{~kg}$ (see Appendixes A and B for SST and DST plutonium inventories, respectively). Stated differently, all the plutonium within the Hanford Site tank farms could be stored in a single tank without exceeding subcritical conditions if lateral homogeneous conditions prevail and if there is no significant local concentration that exceeds $2.6 \mathrm{~g} \mathrm{Pu} / \mathrm{L}$.

When the minimum volumetric subcritical concentration criterion of $2.6 \mathrm{~g}$ $\mathrm{Pu} / \mathrm{L}$ is applied, the total plutonium per meter of depth in a 22.9-m-diameter tank would be $1,070 \mathrm{~kg}$. In other words, a homogeneous $\mathrm{s} 7 \mathrm{ab}$ approximately $1 \mathrm{~m}$ in depth in a single large tank could contain the entire worst case estimated amount of plutonium sent to the tank farms and remain subcritical. To put this into perspective, the maximum plutonium inventory in any tank is estimated to be 7 ess than $100 \mathrm{~kg}$ (tank 241-C-106).

If it is assumed that a tank contains $100 \mathrm{~kg}$ of plutonium (the approximate value of the highest estimated plutonium inventory for tank 241-C-106) and the plutonium is uniformly distributed within the solids in a $3.8 \mathrm{E}+06 \mathrm{~L}$ (1 million gallon) tank that is one-half full of solids, the plutonium concentration would be approximately $0.05 \mathrm{~g} / \mathrm{L}$. If the entire plutonium content of the tank is concentrated by some mechanism by a factor of 100 with a resulting concentration of $5 \mathrm{~g} \mathrm{Pu} / \mathrm{L}$ and collected in a spherical geometry (the most reactive and conservative configuration), the resulting critical sphere would be approximately $3.1 \mathrm{~m}$ in diameter. Only 13 SSTs and 1 DST have sludge layers equal to or greater than $3.1 \mathrm{~m}$ (Braun et al. 1994).

Because the fissile material remains relatively uniformly dispersed in the waste form at the time of addition to the tanks, the conclusion is that the waste will remain subcritical based on insufficient fissile material concentration. The other factors discussed in this section qualitatively add to this conclusion. Consequently, the only way for an accidental criticality to become possible is for significant concentration mechanisms to occur during the waste aging process. Section 3.0 provides an evaluation of the chemical and/or physical phenomena and mechanisms that could potentially lead to the 
separation and concentration of plutonium from neutron absorbers. The section concludes that concentration mechanisms that have been identified cannot result in the required concentration of fissile material (factors of 40 or greater) necessary to result in a risk of an accidental criticality.

\subsection{CRITICALITY PERSPECTIVES FOR WASTE HETEROGENEITY}

An in-depth analysis of chemical, physical, and mechanical processes was performed to evaluate the feasibility of separation and concentration of fissile material from the neutron-absorbing sludge fraction. A summary of chemical and physical properties evaluated as to their effect on precipitation and dissolution includes the following:

- Hydrolysis (pH effects)

- Complexation (including inorganic and organic ligands)

- Ionic strength

- Oxidation - reduction

- Temperature

- Radiolysis.

Chemical and physical properties evaluated as to their effect on the sorption and/or desorption of fissile materials onto waste solids includes the following:

- Initial state of main substrates

- Substrate recrystallization/aging

- $\mathrm{pH}$ effects

- Complexation effects

- Ionic strength effects

- Oxidation-reduction effects

- Temperature effects

- Radiolysis effects.

Ore formation mechanisms were also evaluated to determine whether fissile materials may behave similarly to concentration mechanisms of rare elements into localized areas.

Mechanical processes evaluated to determine feasibility of separation/concentration of discrete fissile particles were based on operational activities including the following:

- Fluid dynamics--amount of energy needed to dislodge particies

- Differential settling of particles during tank loading and intermittent additions

- Differential settling of particles during cascading

- Differential settling/redistribution caused by air 7 ift circulation pumps

- Differential redistribution caused by salt well pumping 
- Differential redistribution caused by jet nozzle mixer pumps

- Differential redistribution caused by sluicing

- Physical impacts of aging (densification)

- Temperature effects (convection cells)

- Ore purification analogue (e.g., gold placer mining/froth flotation).

In addressing potential plutonium concentration mechanisms, the technical analysis was evaluated based on (1) concentration potential during the transfer of waste into the tanks, and (2) concentration mechanisms that might occur within the tanks. For both circumstances, the summary discussion in Section 3.0 first considers physical considerations and then focuses on chemical aspects. Detailed results and discussions are presented in Serne et a1. (1996). 
WHC-SD-WM-TI-725

Revision 0

\subsection{WASTE TANK HISTORY WITH RESPECT TO CRITICALITY HAZARD}

\subsection{WASTE TO TANKS}

This section describes the physical and chemical considerations of waste to tanks.

\subsubsection{Physical Considerations}

From startup in 1943 until 1988, the primary mission at the Hanford Site was to produce weapons- or fuels-grade plutonium. There was a very strong incentive to maximize plutonium production and to minimize the amount of this valuable product sent to waste storage tanks. Separations plant managers had a strong incentive to keep plutonium waste losses very low because their performance was at least partially determined by the plant output of pluton ium.

During the 45 years of plutonium production and separation, plutonium-bearing wastes were distributed to many tanks and no intentional concentration operations were performed. The potential for plutonium criticality problems was recognized early on. Specifications for liquid wastes to be routed to underground storage always limited the plutonium concentration to a very low value. Furthermore, in nearly all cases, a large mass of neutron absorbers (e.g., iron) was sent to storage tanks along with the small mass of plutonium. Such neutron absorbers were typically added as part of the chemical processes used to recover plutonium from the irradiated reactor fuel.

Plutonium-containing wastes routed to the Hanford Site underground storage tanks were generated from five different chemical processes (plants) operated at the Hanford Site from 1944-88. A description of the chemical processes and plutonium concentration associated with each of the waste streams is identified in Serne et a1. (1996).

- Bismuth phosphate process (B and T Plants)

- Reduction-oxidation (REDOX) process (S P1ant)

- Metal recovery process (U Plant)

- Plutonium Uranium Extraction (PUREX) process

- Plutonium Finishing Plant (PFP).

These processes routinely discharged wastes to the tanks in the form and composition specified in chemical process flowsheets for the individual processes. To avoid excessive corrosion of the mild steel tanks, all process wastes were made alkaline before routing to the underground tanks. Various metal hydroxides and hydrated oxides were formed when sodium hydroxide was added to the acidic waste solutions. Pumps and steam jets were used to transfer neutralized wastes to tanks and, in some cases, between tanks. To ensure compatibility with jetting or pumping equipment, all process-generated waste solutions and slurries were kept intentionally dilute.

The bismuth phosphate process did not recover uranium; uranium in the $B$ and T Plants was thus routed to the underground tanks. During 1954-57, the 
valuable uranium was reclaimed by hydraulic sluicing and then transported to the $U$ Plant. There the waste was acidified with nitric acid, and the uranium recovered and purified by a tributyl phosphate (TBP) solvent extraction process. Small amounts of plutonium in the acid feed to the TBP extraction process were not recovered. The acidic waste from the U Plant TBP extraction process was made alkaline and routed to tanks in the tank farms.

Two important aqueous waste streams were generated by the REDOX process:

- Cladding waste

- High-level waste.

The cladding waste was generated by chemically dissolving aluminum cladding in a $\mathrm{NaOH}-\mathrm{NaNO}_{3}$ solution. This waste typically contained about $450 \mathrm{~g}$ of uranium per ton of fuel processed and the uranium/plutonium mass ratio was typically about 530. The neutralized high-level waste contained $6.8 \mathrm{~kg}$ of iron per ton of fuel processed at an iron/plutonium mass ratio of about 358 . The iron/plutonium weight ratio for the high-level waste was higher than the value of 160 required (see Section 2.2.1) to maintain subcriticality conditions. Although the uranium/plutonium ratio for the cladding waste was below the minimum value (770) to ensure subcriticality conditions, the concentration of plutonium in this waste was also kept well below the $2.6 \mathrm{~g}$ $\mathrm{Pu} / \mathrm{L}$ minimum subcritical concentration criterion (see Section 2.1).

During its operational period, the Hanford Site PUREX P1 ant reprocessed Al- and zircaloy-clad uranium metal fuel. In addition to generating two types of high-level wastes, several low-level waste streams, e.g., cladding wastes, laboratory wastes, and solvent wash wastes, were generated. All these waste streams were made alkaline and routed to tanks in the tank farms.

After addition of sodium hydroxide, the high-level waste (neutralized current acid waste) from processing of Al-clad fuel contained $3.7 \mathrm{~kg}$ of iron per ton of fuel processed, equivalent to an iron/plutonium weight ratio of 28,500 . The $10 \mathrm{w}-1$ evel wastes generated during such processing contained $719 \mathrm{~g}$ of uranium per ton of fuel processed, equivalent to a uranium/plutonium weight ratio of 850 .

The high-level waste resulting from the processing of zircaloy-clad uranium metal fuel contained $8,400 \mathrm{~kg}$ of iron per ton of fuel processed, equivalent to an iron/plutonium weight ratio of 2,520. The corresponding low-level wastes contained $2,140 \mathrm{~g}$ of uranium per ton of fuel processed, equivalent to a uranium/plutonium weight ratio of 290 . The plutonium concentration in the neutralized current acid waste generated in processing either Al- or zircaloy-clad fuels did not exceed $0.003 \mathrm{~g} \mathrm{Pu} / \mathrm{L}$.

Beginning in 1981, acidic wastes generated in the PFP operations were made alkaline before routing to the $241-T X-244$ salt well receiver tank and then to tank 24I-SY-102. During limited cleanout operations in 1981, the PFP started regularly adding iron to its acidic waste to meet the 1 vol\% total solids requirements specified by tank farm criticality considerations. The wastes generated in the PFP solvent extraction operations contained significant concentrations of aluminum. Typically, in neutralized solvent extraction waste, the aluminum/plutonium weight ratio was 723 . 
Table 3-1 lists the absorber-to-plutonium mass ratios in the waste streams from the various fuel reprocessing and separations plants just discussed. Calculated minimum mass ratios to ensure subcriticality are listed in Tables 2-1 and 2-2 (see Section 2.2.1).

Figure $3-1$ is an illustration of the six principal waste types from the respective processes. For instance, waste from fuel decladding was collected from the bismuth phosphate (B and T Plants), REDOX (S Plant), and PUREX processes. In the latter case, two types of cladding were processed, i.e., aluminum and zircaloy. Shown below each of the waste streams are the absorber-to-plutonium ratios $(X: P u)$ based on the flowsheet composition for each relevant waste stream from each of the plants for every instance in which the absorber to plutonium ratio exceeds that required to ensure subcriticality (Serne et a1. 1996). The minimum ratios necessary to ensure subcriticality for each absorber type are summarized at the bottom of the graphic. This figure graphically illustrates that each waste stream contains sufficient neutron absorbers of at least one type to maintain a subcritical composition, irrespective of any other conditions. In many cases, there is more than one neutron absorber type present in sufficient quantities to provide this safety factor. Beyond this, the neutron absorption that occurs from elements not sufficiently plentiful to guarantee subcriticality on their own add considerably to the subcriticality margin based on the sum of the individual absorber fractions as noted in Section 2.2.1.

In summary, there is abundant evidence that all the waste streams sent to the Hanford Site underground tanks contained only very small amounts of plutonium. Furthermore, the concentrations of various neutron absorbers, e.g., iron, uranium, etc., in the waste streams were consistently high either because they were an intrinsic part of each of the wastes or because they were deliberately added for criticality control. Detailed information concerning the volume and composition of all the waste streams sent to the underground tanks is provided in Anderson (1990) and Hanlon (1993) and references cited therein.

Table 3-1. Mass Ratios in Selected Waste Streams Sent to the Tank Farms.

\begin{tabular}{|c|c|c|c|c|c|c|}
\hline \multirow{2}{*}{ Origin of wastes } & \multicolumn{2}{|c|}{$\mathrm{U} / \mathrm{PU}$} & \multicolumn{2}{|c|}{$\mathrm{Fe} / \mathrm{Pu}$} & \multicolumn{2}{|c|}{$\mathrm{Al} / \mathrm{Pu}$} \\
\hline & Measured & $\underset{\text { critical }}{\text { Min. }}$ & Measured & $\operatorname{Min}_{\text {critical }}$ & Measured & $\begin{array}{l}\text { Min. } \\
\text { critical }\end{array}$ \\
\hline $\begin{array}{l}\text { REDOX } \\
\text { Cladding waste } \\
\text { High-level waste }\end{array}$ & $\begin{array}{l}531 \\
\cdots\end{array}$ & $\begin{array}{l}770 \\
--\end{array}$ & $\begin{array}{l}-- \\
358\end{array}$ & $\overline{160}$ & $\because-$ & 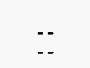 \\
\hline $\begin{array}{l}\text { PUREX } \\
\text { AL-clad fuel } \\
\text { High level } \\
\text { Low level } \\
\text { Zr-clad fuel } \\
\text { High level } \\
\text { Low level }\end{array}$ & 849 & $\begin{array}{c}-. \\
770 \\
-- \\
770\end{array}$ & $\begin{array}{c}28,500 \\
\ldots \\
2,524 \\
\ldots\end{array}$ & $\begin{array}{c}160 \\
-- \\
160 \\
\cdots\end{array}$ & $\begin{array}{l}-- \\
-- \\
-- \\
--\end{array}$ & $\begin{array}{l}\cdots \\
\cdots \\
--\end{array}$ \\
\hline PFP & -- & - & $\cdots$ & $\cdots$ & 723 & 910 \\
\hline
\end{tabular}

PFP $=$ Plutonium Finishing Plant PUREX = Plutonium Uranium Extraction REDOX = Reduction-oxidation 


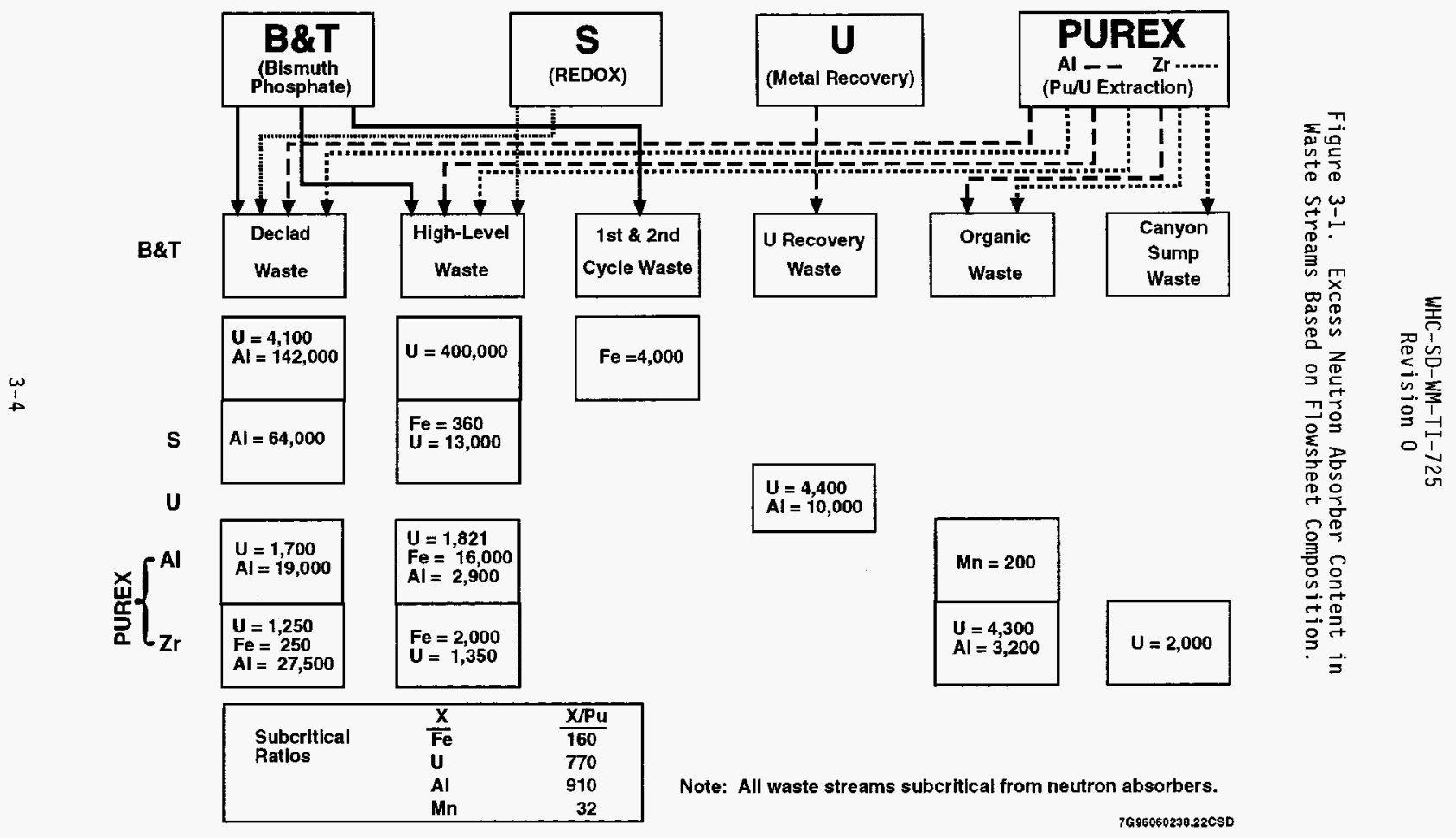


Further confirmation that plutonium in the Hanford Site tanks is associated with large amounts of various neutron absorbers is provided by the data in Table 3-2. These values are taken from Braun et al. (1994). In addition to the major constituents, iron and aluminum, wastes routed to the tanks also contained various concentrations of other metals, e.g., uranium, zirconium, manganese, nickel, chromium, etc., all of which function, to a greater or lesser degree, to absorb neutrons.

\subsubsection{Chemical Considerations}

If acidic waste solutions had contained $\mathrm{Pu}$ (IV) as the only dissolved metal ion, addition of sodium hydroxide would have produced plutonium polymer ${ }^{*}$ and plutonium hydroxide. Typical concentrations of plutonium in the acid wastes ranged from $1.0 \times 10^{-6}$ to $1.0 \times 10^{-5} \mathrm{~g} \mathrm{Pu} / \mathrm{L}$. At these low plutonium concentrations, incipient polymerization of plutonium requires a relatively high $\mathrm{pH}$. Also, polymerization is not instantaneous, but requires an induction period before plutonium polymer is formed. Although polymer formation is unlikely, any polymer that is formed has a strong affinity to adhere to other particles suspended in solution or on nearby surfaces. The actual wastes contained not only Pu(IV) but much higher concentrations of metals such as iron and others whose hydroxides are quite insoluble. Under

Table 3-2. Typical Mass Ratios in Waste Tanks. ${ }^{\text {a }}$

\begin{tabular}{|l|c|c|}
\hline \multirow{2}{*}{ Origin of waste } & $\mathrm{Fe} / \mathrm{Pu}$ & $\mathrm{Al} / \mathrm{Pu}$ \\
\cline { 2 - 3 } & Mass ratio & Mass ratio \\
\hline Bismuth phosphate & 2,800 & 3,200 \\
\hline RED0X & 330 & 15,000 \\
\hline PUREX & -- & -- \\
\hline Aluminum-clad & 15,000 & 160,000 \\
\hline Zircaloy-clad & 770 & 1,500 \\
\hline PFP & $23^{\mathrm{b}}$ & 840 \\
\hline
\end{tabular}

Minimum mass ratios for criticality are 160 for $\mathrm{Fe} / \mathrm{Pu}$ and 910 for $\mathrm{Al} / \mathrm{Pu}$. control.

${ }^{\mathrm{b}}$ This does not include iron added for criticality

PFP = Plutonium Finishing Plant

PUREX = Plutonium Uranium Extraction

REDOX = Reduction-oxidation

*Most chemists now consider this species to be colloidal $\mathrm{Pu}(\mathrm{OH})_{4}$ that will eventually coagulate and settle, especially under alkaline conditions. 
WHC-SD-WM-TI-725

Revision 0

these conditions; addition of sodium hydroxide to the acidic wastes precipitated iron and other nonradioactive metal hydroxides to form what is termed "sludge."

The three potential chemical mechanisms that need to be considered in determining the manner in which plutonium enters the sludge phase (Figure 3-2) are as follows:

- Sorption onto precipitated metal oxide sludge particles

- Precipitation as pure plutonium oxide crystals

- Formation of solid-solid solutions with non-neutron absorbers such as $\operatorname{Zr}(\mathrm{IV})$ and $\mathrm{Bi}(\mathrm{III})$.

During the long time that the sludges have aged in the tanks, the solids have attained a higher degree of crystallinity as the result of collapse of metal hydroxide bridges to metal oxide bridges by elimination of water.

Figure 3-2 illustrates how the different mechanisms by which plutonium entered the sludge are related to subcritical operations.

If sorption were the dominant mechanism, bonding of plutonium to strong neutron-absorbing metals such as iron and manganese provides direct assurance that an accidental tank criticality cannot occur. If pure hydrous plutonium oxide formed as a crystalline precipitate when acidic wastes were made alkaline, the plutonium oxide particles would be expected to agglomerate or mix with neutron absorbers. For nuclear criticality to occur, large (tens of micrometers in size) plutonium particles free of neutron absorbers must be created and then concentrated by some hydraulic force. All literature data and hydraulic modeling calculations performed to date (see Section 3.4) indicate that creation and separation of such plutonium-bearing particles are not plausible.

Another co-precipitation mechanism is solid solution formation in which a plutonium ion can replace an ion of a metal present at a higher concentration in a crystalline lattice. Because the ionic radius of Pu(IV) differs so much from those of $\mathrm{Fe}$ (III) and $\mathrm{Al}$ (III), solid solution may be discounted for these latter ions. However, ionic radii of $\mathrm{Pu}$ (IV), $\mathrm{Zr}$ (IV), La(III), and Bi(III) are quite similar. Thus, it is possible that some solid solution occurred in wastes containing these latter three ions, e.g., zircaloy cladding waste and $\mathrm{BiPO}_{4}$ process waste. But even these latter waste solutions contained large concentrations of $\mathrm{Fe}$ (III) so that in addition to solid solution formation with $\operatorname{Zr}($ IV), Bi(III), or La(III) some of the plutonium could have co-precipitated with hydrated iron oxide.

The remaining discussion in Section 3.0 expands on various facets of the chemistry of plutonium in waste sludges (and also in salt cake and interstitial liquid) both as initially formed and during and after aging in the tanks. Much more detailed information, including extensive citations to the original literature, concerning relevant plutonium chemistry is provided in a recent report regarding criticality issues involved in transferring some of the waste in tank 241-C-106 to tank 241-AY-102 (Waltar et a1. 1996).

Liberal use is made in this report of technical information contained in the latter reference. 
Figure 3-2. Chemical and Physical Considerations Related to Tank Criticality.

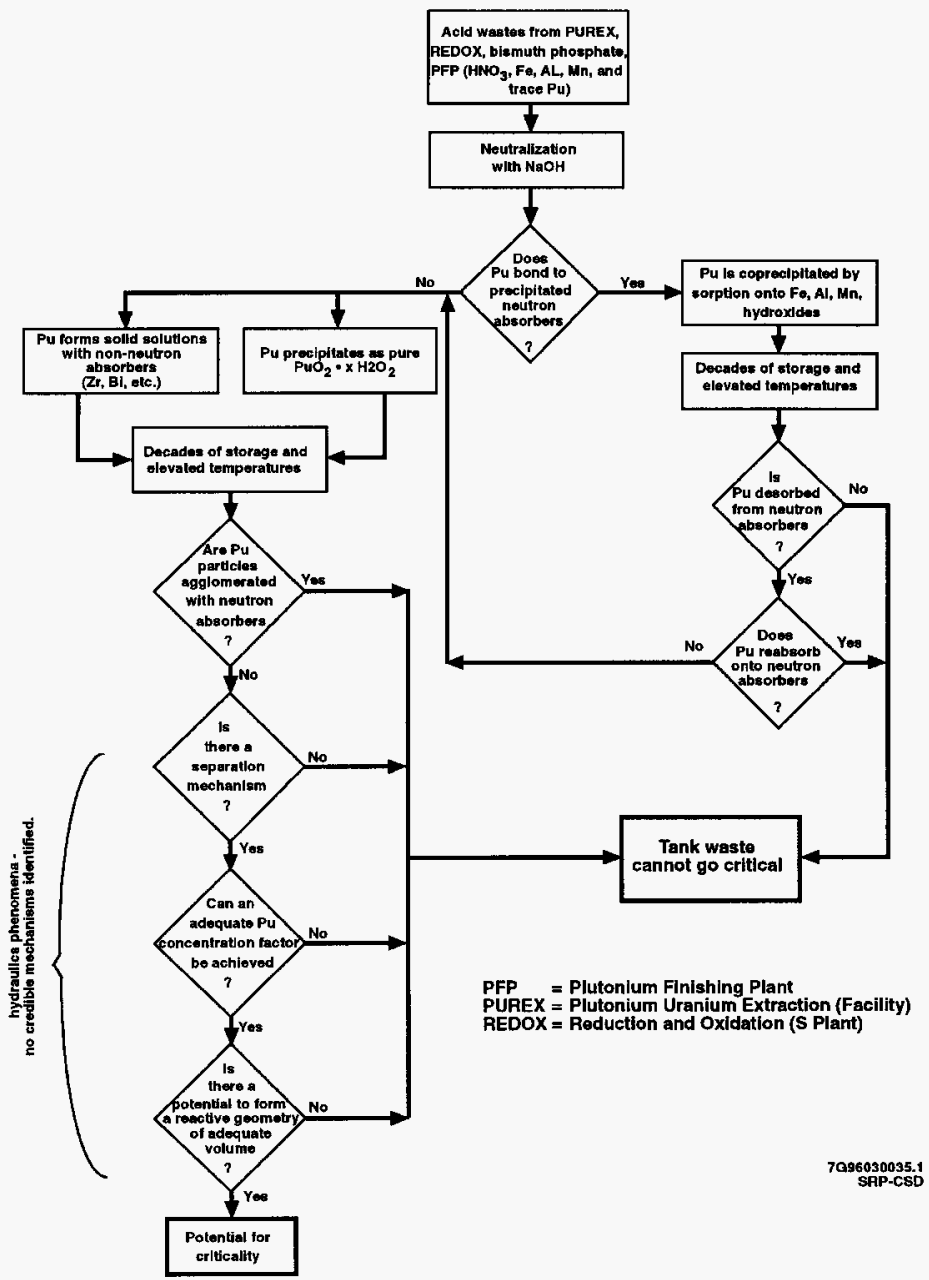


WHC-SD-WM-TI-725

Revision 0

Table 3-3 compares solubilities of amorphous $\mathrm{PuO}_{2} \cdot \mathrm{xH}_{2} \mathrm{O}$ (Rai et a1. 1980), amorphous $\mathrm{Fe}(\mathrm{OH})_{3}$ (Lindsay 1979), and crystalline $\mathrm{Al}(\mathrm{OH})_{3}$ (gibbsite) (Lindsay 1979) for a range of $\mathrm{pH}$ values. These solubility data show that iron will precipitate as iron oxyhydroxide before any plutonium can precipitate as plutonium oxyhydroxide during the waste neutralization process assuming no significant kinetic differences. Because the wastes contain thousands of times more iron and aluminum than plutonium, a pure plutonium phase (plutonium hydroxide or polymer) is not likely to form. Rather, the plutonium is expected to be coprecipitated by sorption on the iron and aluminum hydroxides that precipitate first in much larger quantities.

The rate of iron hydroxide precipitation during waste neutralization is rapid compared to the rate of plutonium hydroxide precipitation (or plutonium hydroxide polymer formation). As long as the initial molar ratio of $\left[\mathrm{OH}^{-}\right] /\left[\mathrm{Fe}^{3+}\right]$ is greater than 3 , amorphous $\mathrm{Fe}(\mathrm{OH})_{3}$ will precipitate immediately (Yariv 1979). During neutralization of the acidic wastes, this ratio greatly exceeded 3. Toth et a1. (1981) have shown that the rate of plutonium hydroxide polymer formation is slow at the plutonium concentrations known to exist in the acidic wastes and that the rate of polymer formation decreases with decreasing plutonium concentration.

Because other insoluble oxyhydroxides precipitated in great excess with plutonium oxyhydroxide, co-precipitation of plutonium with the sludge-forming solids occurred. Several likely co-precipitation mechanisms are important. The most important mechanism is believed to be sorption of plutonium oxyhydroxide on the solid metal oxyhydroxides. In particular, the oxyhydroxides of iron and aluminum develop large, amorphous surfaces as they are formed that attract transition metal ions (Laitinen 1960). It is possible that some plutonium absorbed on the oxyhydroxides of metals other than iron and aluminum, e.g., zirconium, lanthanum, nickel, chromium, etc. Except for the wastes generated by the dissolution of zircaloy cladding and by routine washing of PUREX process solvent, iron and aluminum concentrations of wastes routed to underground storage tanks were much higher than the other metals that formed oxyhydroxides. From simple statistical considerations, therefore, it is likely that any plutonium oxyhydroxide formed in the waste sorbed on the oxyhydroxides of iron and aluminum rather than on other metal oxyhydroxides. There is no experimental evidence to suggest that plutonium oxyhydroxide was preferentially sorbed by a metal oxyhydroxide present in only small amounts. Similarly, there are no known theoretical considerations that indicate preferential sorption of plutonium oxyhydroxide on one metal oxyhydroxide over another.

Another possible precipitation mechanism is formation of individual crystals of $\mathrm{PuO}_{2} \cdot \mathrm{xH}_{2} \mathrm{O}$, despite the presence of many other constituents that could precipitate. Small amounts of plutonium oxide were added to tank 241-SY-102. This plutonium oxide represented material that did not dissolve during processing of various plutonium scraps. The plutonium oxide 
Table 3-3. Comparison of Plutonium, Iron, and Aluminum Hydroxide Solubilities.

\begin{tabular}{|c|c|c|c|c|}
\hline \multirow[b]{2}{*}{$\mathrm{pH}$} & \multicolumn{4}{|c|}{ Log of solubilities (M) } \\
\hline & $\mathrm{PuO}_{2}{ }^{\circ} \times \mathrm{H}_{2} \mathrm{O}$ & amorphous) & (Fe(OH) 3 , amorphous) & $\left(\mathrm{Al}(\mathrm{OH})_{3}\right.$, crystalline) \\
\hline $\begin{array}{l}3 \\
4 \\
5 \\
6 \\
7 \\
8 \\
9\end{array}$ & $\begin{array}{l}-3.6 \\
-4.5 \\
-5.3 \\
-6 . \\
-6.8 \\
-7.6 \\
-8 .\end{array}$ & & $\begin{array}{r}-5.5 \\
-7.1 \\
-8.0 \\
-9.2 \\
-10.0 \\
-10.3 \\
-10.0\end{array}$ & $\begin{array}{l}-1 \\
-3 \\
-6 \\
-7 \\
-7 \\
-7 \\
-6\end{array}$ \\
\hline
\end{tabular}

remained suspended in feeds to the TBP solvent extraction process and eventually reported to the aqueous raffinate. The raffinate containing the finely divided plutonium oxide particles was neutralized with sodium hydroxide and the resulting slurry eventually was routed to tank 241-SY-102.

\subsection{WASTE TANK CHARACTERIZATION ANALYSES}

Irradiated fuels reprocessed in the Hanford Site separation plants contained about 62.7 MT of plutonium. Of this total, 2.7 MT were purified in bismuth phosphate process plants, 11.3 MT were separated and purified in the REDOX Plant, and the remainder was processed in the PUREX Plant.

Roetman et a1. (1994) estimated that the 177 underground tanks at the Hanford Site may contain about $500 \mathrm{~kg}$ of plutonium. However, for conservatism and because of uncertainties in the volume and composition of discharged wastes, Roetman et al. (1994) state that, for use in evaluation and analysis of nuclear criticality issues in tanks, the plutonium inventory should be taken as $1,000 \mathrm{~kg}$. Appendixes $A$ and $B$ provide a tank-by-tank plutonium inventory for the 149 SSTs and 28 DSTs, respectively.

Appendix A provides the plutonium inventory and neutron absorber to plutonium ratio for all SSTs. Analyses of selected tank waste samples and process waste stream modeling have been used to estimate the plutonium and neutron absorber content. The waste volume status summary in Column 1 for sludges, salt cakes, and liquids is from Hanlon (1996). Columns 2, 3, 4, and 5 provide the SST plutonium inventory from four documented evaluations:

- Column 2--Source term plutonium values based on selected waste sample analytical results for sludge, salt cake, and supernatant as documented (Brevick 1995)

- Column 3--Modeled plutonium inventory values based on estimated waste stream input values and waste sample analysis results as documented in the Hanford Defined Waste (HDW) model (Agnew 1996)

- Column 4--Plutonium values based on the indicated available waste sample analyses from the WESTREN analysis (Van Vleet 1993) 
- Column 5--Modeled plutonium inventory values from the TRAC model (Jungfleisch 1993).

An asterisk denotes that a 22.9-m-diameter tank contains greater than $10 \mathrm{~kg}$ plutonium from any one of the four reports. The HDW Ratio Sum listed in Column 6 is based on the HDW model estimates of plutonium and absorber materials (Agnew 1996). This value is calculated from the sum of the ratios of total soluble and insoluble neutron absorbers to plutonium in the sludge fraction for each SST (see Section 2.2.1). For example, a ratio sum of 5 indicates that there is 5 times the required neutron absorber material present to ensure subcriticality. The neutron absorber to plutonium ratio sum is greater than 1 for all SSTs which indicates the margin of subcriticality. This is consistent with the chemical processing flowsheet analys is results previously discussed in Section 3.1.1 and summarized in Figure 3-1.

Appendix B provides the plutonium inventory and neutron absorber to plutonium ratio sum for all DSTs. Column 1 provides the most recent waste volume status as reported by Hanlon (1996). Column 2 provides the most recent plutonium inventory for each DST as estimated in the HDW model (Agnew 1996). Column 3 provides the baselined inventory value as determined from the DST plutonium inventory tracking system, tank characterization measurements, tank transfer records, and the estimated average concentration values for various types of waste (Tusler 1995). The neutron absorber to plutonium ratio sum for each DST is calculated in Column 4. A ratio sum noting "not applicable" (NA) indicates no sludge is present in the respective tanks. The ratio sum is greater than 1 for all DSTs which indicates the margin of subcriticality.

Of the SSTs, tank 24l-C-106 contains the largest amount of plutonium while tank 24l-SX-115 contains the highest measured plutonium concentration in sludge, $0.194 \mathrm{~g} \mathrm{Pu} / \mathrm{L}$. However, even this plutonium concentration is a factor of about 14 below the minimum required for nuclear criticality. In most of the other SSTS, the plutonium concentration in supernatant solution and in sludges and salt cake is 2 orders of magnitude below the minimum subcritical concentration criterion of $2.6 \mathrm{~g} \mathrm{Pu} / \mathrm{L}$.

\subsection{WASTES STORED WITHIN THE TANKS AND THE WASTE AGING PROCESS}

Discussions of the physical and chemical considerations affecting wastes within the tanks are discussed in the following order: (1) sludge, (2) supernatant liquid, and (3) salt cake.

\subsubsection{Sludge}

This section describes physical and chemical considerations of sludge.

3.3.1.1 Physical Considerations. Because of the very low solubility of plutonium in the alkaline tank supernatant 1 iquid, sludges contain much more plutonium than either salt cakes or interstitial liquids. Thus, the focus of this analysis is on the in-tank physical and chemical behavior of sludges. 
WHC-SD-WM-TI-725

Revision 0

As noted earlier, the concentration of plutonium in wastes that entered the tanks was very small compared to metals such as iron, aluminum, and many others.

It is conceivable that temperature differences in the sludge could provide a driving force to transport plutonium along a temperature gradient. For most tanks, however, temperature differences (delta Ts) in the sludge layer are small, with only a difference of a few degrees from the top of the sludge to the bottom. For a few high-temperature tanks, e.g., 241-C-106 and 241-SX-108, maximum delta temperatures in the sludge layer are 19 and $16{ }^{\circ} \mathrm{C}$, respectively (based on thermocouple measurements). If plutonium is present in solid form as discrete solids (the solubility of these solids is estimated to show little sensitivity to temperature), preferential concentration of plutonium along a thermal gradient would require that advective cells form that can move particles. Such an event would require much larger temperature gradients than have been measured. Alternatively, the plutonium may be absorbed on the oxyhydroxide surfaces for which temperature effects on sorption/desorption are considered to be minimal.

Measurements of plutonium distribution coefficients for sorption on geologic material over a $60^{\circ} \mathrm{C}$ range showed an almost insignificant effect of temperature (DOE 1988). Further, the few data available on plutonium solubility do not show significant differences for plutonium oxide and known aqueous species over the temperature range of 25 to $100{ }^{\circ} \mathrm{C}$. Because plutonium would have to be concentrated by orders of magnitude to approach criticality, a thermal driving mechanism is very unlikely. Furthermore, because the sludge layers typically have slab-like layers and the temperature gradient is mainly vertical, the plutonium concentration, if it could occur at all, would result in a relatively thin, flat layer on the top or bottom of the sludge, dependent on whether plutonium is more or less soluble at high or low temperature. This latter configuration is subcritical except for very high concentrations of plutonium.

Whyatt et al. (1996) also discuss how agglomeration can prevent segregation of fissile material particles from neutron-absorbing solid particulates. This study notes that there is very strong evidence that the waste particles will randomly agglomerate with each other which will prevent the concentration of fissile material from occurring. The most direct evidence of this is a comparison of transmission electron microscopy data with measured sedimentation velocities and particle size data. In addition, conservative calculations lead to the conclusion that rapid formation of flocculants will prevent segregation of the fissile material. The study notes that while agglomerates within the waste are likely to be broken up by the hydraulic force of strong pumps, hot cell settling tests imply that agglomerates will reform quickly once mechanical disruption (e.g., mixing) is stopped. This available evidence strongly suggests that the plutonium will be agglomerated with other neutron-absorbing material and cannot be segregated or concentrated from the waste, thus preventing accident criticality.

3.3.1.2 Chemical Considerations. As sludges aged in the underground tanks in which they were formed, they underwent a process called "Ostwald Ripening." This well-known phenomena involves conversion of amorphous or microcrystalline material into more stable crystalline assemblages of larger particle sizes. In the case of Hanford Site sludges, 0stwald Ripening can be regarded as 
conversion of hydroxide bonds between metal atoms, including plutonium, to stronger oxide bonds. Thus, over time, freshly precipitated amorphous iron(III) hydroxide, which is readily soluble in dilute nitric acid, slowly converts to iron oxides, e.g., hematite and goethite, that occur in nature and which are only slightly soluble in nitric acid media. Similarly, freshly precipitated amorphous aluminum hydroxide converts over time to stable gibbsite and boehmite phases. Other metal oxyhydroxides, e.g., those of zirconium, lanthanum, nickel, manganese, etc., that were present in the initial sludge layer also underwent the 0stwald Ripening process.

Plutonium oxyhydroxide, initially present as a separate phase or strongly sorbed on the surface of the various nonradioactive metal oxyhydroxides, also was subjected to changes as the oxyhydroxides converted to stable oxides. If present initially as a separate phase, plutonium oxyhydroxide would eventually convert to plutonium oxide. Any sorbed plutonium oxyhydroxide may have remained with its original substrate as the entire assemblage underwent ostwald Ripening to a crystalline phase or perhaps would be released as the oxides become more crystalline. Released plutonium could form discrete plutonium hydrous oxides that also age toward more crystalline, less soluble solids. Evidence discussed in Section 3.4 indicates that plutonium is very tightly held by aged sludges and little, if any, is removed by leaching with alkaline or nitric acid solutions. This latter evidence suggests that, as sludges aged, the forces binding plutonium to iron and other metal oxyhydroxides increased as the result of the formation of oxide bridges between the plutonium and metal atoms or that discrete plutonium oxide aged to less soluble, more crystalline solids. Unfortunately, modern instrumental probes are not sufficiently advanced to determine exactly how plutonium is held in the actual sludges of various types of atoms and whether plutonium metal atoms are bound to other oxides or are present as discrete pure phase plutonium oxide.

It can be conjectured that small amounts of crystalline phases formed by 0stwald Ripening of metal (other than iron and aluminum) oxyhydroxides containing sorbed plutonium oxyhydroxide have densities different from (higher than) those of the bulk iron and aluminum oxide phases. If so, some separation of different plutonium-bearing solid phases may have occurred over time by natural gravitational forces.

\subsubsection{Supernatant Liquid}

This section describes the physical and chemical considerations of supernatant 1iquid.

3.3.2.1 Physical Considerations. Within liquid portions of any tank, therma? gradients will tend to promote mixing. Consequently, this region of the tank should be relatively homogeneous in composition.

3.3.2.2 Chemical Considerations. The vast majority of liquids added to the underground tanks were aqueous solutions of soluble nitrates resulting from neutralization of waste streams containing nitric acid. The concentration of plutonium in these aqueous solutions were very low because plutonium was efficiently removed as product before waste neutralization. Also, the solubility of plutonium oxyhydroxide is very smal1. Based on solubility 
WHC-SD-WM-TI-725

Revision 0

studies of Yamaguchi et a1. (1994) and Kim et al. (1983), the maximum expected concentrations of dissolved plutonium range from about 0.002 to $0.2 \mathrm{~g} / \mathrm{L}$, depending on the hydroxide and carbonate concentrations in the waste solution. Under waste tank conditions, with nitrite present for corrosion control, the dissolved plutonium species are probably anionic hydroxide and carbonate complexes of Pu(IV).

Some organic liquids used in Hanford Site solvent extraction processes were also added to the underground storage tanks. Much of this liquid was a mixture of TBP and normal paraffin hydrocarbons $\left(C_{10}\right.$ through $\left.C_{14}\right)$. The plutonium concentration in these organic liquids was very small. Also, these organic solvents do not extract plutonium from strongly alkaline solutions.

Organic complexants, e.g., ethylenediaminetetraacetic acid (EDTA), hydroxyethylethylenediaminetriacetic acid (HEDTA), citric acid, glycolic acid, etc., were used in large quantities in ${ }^{90} \mathrm{Sr}$ recovery operations in the 1960 's and 1970 's and, to a lesser extent, in some other waste management operations. These materials were routed to the tanks as part of various process wastes. In the tanks, these compounds have undergone radiolytic and chemical degradation; a large portion has degraded to compounds with simpler molecular structures. Thus, a large number of tanks contain chemicals that have the ability to complex (solubilize) metal cations, including plutonium. Tank supernatant liquids containing high concentrations of organic complexants, e.g., tank 241-SY-101, show little effect of these complexants on increased plutonium concentration, probably because of the high hydroxide ion concentration. The complexing power of such organic reagents decreases with increasing sodium hydroxide concentration. Such organic complexants and sodium carbonate are the primary chemicals in the Hanford Site waste tanks that have the ability to solubilize plutonium.

Tank supernatant solutions cannot hold enough dissolved plutonium to become critical. Organic complexing agents present in some tanks will not affect the plutonium concentrations in supernatant liquids because they are much less effective than either hydroxide or carbonate ions as ligands for plutonium complexation in these solutions. Large carbonate ion concentrations will increase the plutonium concentration in solution, especially in solutions with low free hydroxide contents. Measured hydroxide and carbonate concentration ranges in tank supernatant liquids are from about $4 \mathrm{M}$ to $1.0 \times 10^{-5} \mathrm{M}$ and 1.1 to $0.005 \mathrm{M}$, respectively. The highest concentrations of plutonium from experimental solubility measurements with hydroxide and carbonate concentrations in this range were about $0.2 \mathrm{~g} \mathrm{Pu} / \mathrm{L}$ at $1.1 \mathrm{M}$ carbonate ion and $1.0 \times 10^{-5} \mathrm{M}$ hydroxide. A concentration of plutonium of $0.2 \mathrm{~g} \mathrm{Pu} / \mathrm{L}$ is, of course, well below the $2.6 \mathrm{~g} \mathrm{Pu} / \mathrm{L}$ minimum subcriticality criterion and is far higher than any actual measured plutonium concentration in tank supernatant liquids. If it were possible to increase the plutonium concentration in the supernatant liquid (which lies above the sludge layer) through some transport mechanism, the concentration of plutonium in the sludge layer would be reduced accordingly. Such a result would only further decrease the risk of an accidental nuclear criticality in the sludge layer. 
WHC-SD-WM-TI-725

Revision 0

\subsubsection{Salt Cake} cake.

This section describes the physical and chemical considerations of salt

3.3.3.1 Physical Considerations. The salt cake layers in the tanks were formed by evaporation of dilute solutions of alkaline waste by in-tank solidification or by vacuum evaporation and crystallization. Plutonium concentrations resulting from the evaporation operations were inherently limited by boil-down rates and pumpability considerations. Volume reduction operations resulted in higher concentrations of plutonium in the salt cake than in the original dilute waste solutions. However, most of the concentrated plutonium is in the interstitial liquor retained by the salt cake crystals. Analyses of the interstitial liquor show that plutonium concentrations are far lower than the maximum solubility limit of $0.2 \mathrm{~g} \mathrm{Pu} / \mathrm{L}$. Thus, plutonium concentrations in the actual salt cake are even lower than those in the interstitial liquor.

Salt cake may contain some associated sludge. However, the amounts of sludge trapped within the salt cake are much smaller than the sludge layers themselves. Thus, the sludge layer is the only waste type with a realistic potential for an accidental criticality.

3.3.3.2 Chemical Considerations. The major components of salt cake are sodium nitrate and sodium phosphate that crystallized during evaporation and subsequent cooling of the saturated waste solutions. Any plutonium dissolved in these solutions likely did not reach saturation with respect to plutonium oxyhydroxide solubility; thus, plutonium remained in solution as the sodium salts crystallized. Plutonium does not form a solid solution with any of the crystallized sodium salts and, hence, remained in the interstitial liquor when crystallization was complete. If any plutonium-bearing solutions did become over-saturated, pure phase plutonium oxyhydroxide likely formed. Only insignificant amounts, if any, of plutonium sorbed on the salt surface.

\subsection{PLUTONIUM CONCENTRATION MECHANISMS}

At least one of two changes must occur to depart from the present safe subcritical state to conditions in which an accidental nuclear criticality might occur.

- Certain plutonium-bearing solids, which do not contain significant neutron absorbers other than plutonium, may be present in small amounts in some sludges. The question is whether such solids can be physically separated from other neutron-absorbing sludge components and then redeposited in a geometric shape and volume that would permit nuclear criticality to occur.

- If plutonium is absorbed onto other sludge oxide phases, it must desorb from the sludge where it is tightly bound and concentrate in a 1 iquid phase to a concentration greater than $2.6 \mathrm{~g} \mathrm{Pu} / \mathrm{L}$, or 
precipitate as a discrete plutonium-rich solid that is physically separated from the other sludge solids and then concentrate in a geometric shape and volume that would result in an accidental criticality.

Evidence presented in this section demonstrates that neither of these changes can or will occur in any of the underground storage tanks.

\subsubsection{Physical Considerations}

As discussed in Section 3.3, most of the plutonium in the sludges in the Hanford Site underground tanks is believed to be tightly bound to iron oxides. Iron is, of course, a good neutron absorber. In some sludges, there is a possibility that plutonium is associated with crystalline oxides of metals other than iron, e.g., zirconium, bismuth, etc. These other metals do not function as well as iron in absorbing neutrons.

Densities of crystalline oxides of plutonium, zirconium, bismuth, etc., differ from those of the iron oxides present in siudges. Eventually, gravitational forces may have caused some separation of different sludge solid components. Even so, crystalline oxides of plutonium, zirconium, and bismuth are sti11 mixed with other neutron-absorbing oxyhydroxides (e.g., iron) and are therefore subject to the total macroscopic absorption cross section of these oxyhydroxides (e.g., neutron-absorbing properties of iron).

Several devices (e.g., air lift circulators, mixer pumps, salt well pumps, transfer pumps, etc.) are used to move solids and liquids in some of the Hanford Site tanks and between tanks. All the following criteria have to be satisfied for operation of any of these transport devices/methods to result in a critical plutonium assembly.

- The sludge layer in a particular tank must contain either a discrete plutonium oxide phase or plutonium-bearing oxides or oxyhydroxides of metals that are less efficient neutron absorbers than iron, e.g., zirconium.

- To allow their physical separation, the density and particle size attributes (commonly merged into the parameter noted as settling velocity) of the plutonium oxide and/or oxyhydroxides and/or oxides of relatively poor neutron absorbers must be sufficiently different from oxides and/or oxyhydroxides of metals, e.g., iron, which are good neutron absorbers.

- The total plutonium content of oxide and/or oxyhydroxide phases that can be physicaliy separated from those of iron and other metals that are effective neutron absorbers must represent a critical mass under at least some geometric conditions.

- The entire sludge layer in a tank, or at least a sizable portion thereof, must be mobilized to realize physical separation of a critical mass of plutonium oxide or other plutonium-bearing oxides or oxyhydroxides. 
- The settling velocity (a function of particle size distribution and density) of any separated plutonium oxide and/or plutonium-bearing oxides and oxyhydroxides of inefficient neutron absorbers must be such that, when the sludge in a tank is mobilized, sufficient high settling velocity plutonium-bearing particles to constitute a critical mass will deposit in non-turbulent zones. The non-turbulent zone must be of a size that will contain a critical geometry and volume of material at the achieved concentration.

To further consider physical methods of concentrating plutonium-bearing solids, the following waste tank operational activities are summarized. A more detailed analysis of mechanical processes evaluated based on the operational activities identified in Section 2.4 is provided in Serne et a1. (1996).

Salt Well Pumping. Salt well pumping essentially involves extraction of liquid wastes, containing a subcritical concentration of plutonium, from an SST to a DST where they are dispersed into similar liquid waste also containing a subcritical amount of plutonium. Salt well pumping is accomplished by means of perforated steel pipes inserted vertically at various points in an SST from the top of the waste to the bottom of the tank (Hanson and La Riviere 1981). Liquid waste that enters the pipe is continuously pumped to a DST until the pumping rate falls below a previously determined low rate. Initially, some sludge and salt cake solids are transferred to a DST along with the liquid phase. However, the amount of solid waste transferred in this manner quickly decreases as the bulk solids surrounding the salt well pipe begin to act as a filter media to prevent additional finely divided solids from migrating into the well.

Any solids that are pumped from salt wells in SSTs are introduced into a receiver DST in a controlled manner that disperses them within the DSTs, thus avoiding any potential for accumulation of plutonium-bearing solids in one location. From a nuclear criticality perspective, salt well pumping is a localized and benign activity that does not cause significant separation and/or physical concentration of solid materials. In particular, plutonium oxide and/or plutonium-bearing oxides and oxyhydroxides of metals that are not effective neutron absorbers cannot be effectively concentrated.

Pacific Northwest National Laboratory (PNNL) personnel recently evaluated the potential for salt well pumping to lead to nuclear criticality. They conclude (Serne et al. 1996) ". . . it appears that salt well pumping will not have any impact on particle segregation in single-shell tanks that contain fine grained sludges."

Air Lift Circulators. Air 1 ift circulators are not currently operating in any SST. However, air 1 ift circulators are installed in several DSTs, e.g., 241-AZ-101, 241-AZ-102, 241-AW-102, etc., and are available for use when needed. Air lift circulators are simply vertical steel pipes that are open at both ends. Air is pumped through the pipes to keep sludge solids dispersed in the 1 iquid phase, thereby evening out the heat load in the tanks (Kady and Groff 1983). Historically, air lift circulators have been operated in those tanks where the ${ }^{90} \mathrm{Sr}$ content of the sludge phase was/is significantly high, and 1 arge amounts of heat energy are generated by radioactive decay of ${ }^{90} \mathrm{Sr}$. operation of air lift circulators in such tanks prevents "bumping" and hot 
spots, both of which are objectionable phenomena for safe tank management. Air lift circulators simply redistribute sludges without significantly separating and concentrating phases, e.g., plutonium oxide or plutonium-bearing oxides of zirconium.

Mixer Pumps. Mixer pump modeling studies have been conducted by PNNL personnel using the TEMPEST ${ }^{*}$ code. Modeling studies have been performed for the use of a single rotating jet at the center of a DST as well as for the use of two mixer pumps. No results have been obtained in either case that achieve sufficient separation and concentration of fissile material from neutron absorbers to result in a criticality concern (Serne et al. 1996 and Whyatt et a1. 1996). Note, however, that the TEMPEST code does not model all the physical concentration mechanisms evaluated in the mineral processing industry. Evaluation of these types of mechanistic processes regarding how they might apply to Hanford Site waste tanks has been addressed by evaluating operational principles of gravity separation. Again, no results have been obtained that would achieve sufficient segregation of fissile material or geometry to result in a criticality concern (Serne et al. 1996).

A single mixer pump is operated in tank 24l-SY-101 to prevent accumulation and sudden release of potentially explosive gases. Before startup of the mixer pump in tank 241-SY-101, Los Alamos National Laboratory personnel performed a special safety assessment of proposed operations including the potential for an accidental nuclear criticality (Sullivan 1995, Appendix I). Taking into account that there is only about $1 \mathrm{~kg}$ of plutonium in the sludge in tank 241-5Y-101 and that the plutonium is associated with a large excess of iron and other metals, the Los Alamos National Laboratory analys is concluded that the proposed mixer pump installation and operation would not lead to a nuclear criticality accident. Furthermore, an investigation of hydraulic mechanisms by PNNL scientists indicates that a single pump mixer will not lead to deposition of solids in a compact geometry (Serne et al. 1996). Under these conditions, solids will likely be deposited in an annular ring around the pump mixer.

Finally, large-scale experience in sluicing and transporting sludges from Hanford Site SSTs is of relevance. From 1954-57, aged bismuth phosphate process sludges containing uranium were sluiced and transported to the U Plant for recovery of the uranium. In the 1960's, aged PUREX process sludges were sluiced and later treated with nitric acid to prepare feed for solvent extraction removal of ${ }^{90} \mathrm{Sr}$. Interestingly, solid residues still containing large amounts of plutonium and significant amounts of ${ }^{90} \mathrm{Sr}$ from the 1960 's sludge retrieval and nitric acid dissolution runs were transferred to tank 241-C-106 where they are stored in a critically safe manner.

\subsubsection{Chemical Considerations}

Any chemical mechanism for concentrating the plutonium in a waste tank requires the transport of plutonium from various solid phases to an aqueous liquid phase and then to a compact geometry of a solid phase. Sorbed plutonium must be desorbed into the aqueous phase of the mixture of solid and

\footnotetext{
*TEMPEST is a trademark of Battelle Memorial Institute.
} 
WHC-SD-WM-TI-725

Revision 0

liquid phases in the waste tanks. However, plutonium sorption on oxyhydroxides may be irreversible under certain chemical environments (DOE 1988, Alberts and 0rlandini 1981) unless the solution composition in contact with the plutonium is dramatically altered. Such alteration requires the addition of organic or inorganic plutonium complexants, large changes in the REDOX potential of the solution by addition of oxidants or reductants, or by acidification of the solution.

Potential complexing agents for plutonium are present in all the tanks. organic complexing agents such as EDTA, HEDTA, nitrilotriacetate, citrate, oxalate, and others are in the various waste mixtures. Even though these compounds are powerful complexants for plutonium in weakly acidic solutions, they are not very effective at the high hydroxide ion concentrations of actual waste supernatant 1 iquids (Delegard et a1. 1984). Under alkaline conditions, the organic reagents cannot compete strongly with either hydroxide or carbonate ion bonding to plutonium ions. Anionic complexes of Pu(IV) with hydroxide and carbonate ion have been shown to. form under conditions expected in waste tank supernatant liquors. With excess nitrite ions the proposed aqueous species are $\mathrm{Pu}(\mathrm{OH})_{2}\left(\mathrm{CO}_{3}\right)_{2}{ }^{(2-)}$ and $\mathrm{Pu}(\mathrm{OH})_{4}\left(\mathrm{CO}_{3}\right)_{2}{ }^{(4-)}$. These species have only very low solubility in waste tank supernatant fiquids so they are not likely to cause significant plutonium desorption.

The supernatant liquids in the underground tanks contain high concentrations of dissolved nitrite ions, relative to plutonium concentrations, that act as a mild reducing agent, maintaining soluble plutonium almost exclusively as Pu(IV). Because Pu(IV) is sorbed more strongly or is more insoluble than either $\mathrm{Pu}(V)$ or $\mathrm{Pu}(\mathrm{VI})$, the nitrite ions help drive the plutonium to the solid phase. To change the reductionoxidation potential of the supernatant liquid requires the addition of huge quantities of oxidizing or reducing agents to the tanks. Such additions are not reasonable in view of the tight control maintained over additions of materials to the tanks.

Dissolution of plutonium oxide to yield solutions containing soluble plutonium concentrations above $0.2 \mathrm{~g} \mathrm{Pu} / \mathrm{L}$, in carbonate solutions at a $\mathrm{pH}$ in the range of 9 to 10 , would require oxidation of $\mathrm{Pu}(\mathrm{IV})$ to either $\mathrm{Pu}(\mathrm{V})$ or $\mathrm{Pu}(V I)$. A very strong oxidant such as $\mathrm{Ag}(\mathrm{II})$, boiling nitric acid, chlorine, permanganate ion, etc., is required to effect such oxidation. Even under carefully controlled laboratory conditions, such oxidation of Pu(IV) is difficult to achieve. Thus, no dissolution mechanism is known to produce a sufficiently high plutonium concentration to be of criticality concern.

Acidification of wastes in the underground tanks could cause some dissolution of oxyhydroxides or oxides of plutonium and other metals on which the plutonium may be sorbed and thus result in dissolution of some of the plutonium. of greater consequence would be the large volume of gases generated by reactions with nitrite ions to produce $\mathrm{NO}_{x}$ gases, with carbonate ions to produce $\mathrm{CO}_{2}$, and with the carbon steel tanks to produce hydrogen gas. Acidification would eventually cause failure of the carbon steel pipelines and steel liner, allowing liquid waste to escape into the environment. Because of these disastrous consequences, accidental acidification of the wastes must be avoided. 
In addition to co-precipitated plutonium, tank 241-SY-102, which receives PFP waste, may also contain small amounts of plutonium oxide. As noted earlier, small amounts of plutonium oxide were not dissolved during preparation of PFP solvent extraction feed from scrap materials and likely were carried over to the raffinate stream from the TBP extraction step. The solubility of $\mathrm{PuO}_{2} \cdot \mathrm{xH}_{2} \mathrm{O}$ in actual waste supernatant liquids is expected to range from 0.002 to $0.2 \mathrm{~g} \mathrm{Pu} / \mathrm{L}$ depending on crystallinity and carbonate $/ \mathrm{pH}$ status. The actual concentration should be lower than these values because of solid solution formation and/or sorption of plutonium on oxyhydroxides that are also present in tank 241-SY-102. The highest measured plutonium concentration in the supernatant in tank $241-S Y-102$ is $0.016 \mathrm{~g} \mathrm{Pu} / \mathrm{L}$. The actual observed value falls within the calculated bounds of the conceptual absorption and solubility models inferred from work with simulated wastes shown in Figure 3-3. Also shown in Figure 3-3 are the relationships between sorption, desorption, and solubility of plutonium in the waste. The heavy line in the figure is the sorption isotherm, which shows that as more plutonium is sorbed on the solid phase, plutonium concentration in the solution phase increases up to the solubility limit for $\mathrm{PuO}_{2} \cdot \mathrm{xH}_{2} \mathrm{O}$. The desorption isotherms are nearly flat because of the irreversibility of the sorption reaction. The position of the desorption isotherm depends on the concentration of plutonium in the solid phase.

All the measured plutonium concentrations in tank supernatant solutions are below the expected solubility of $\mathrm{PuO}_{2}{ }^{-} \mathrm{xH}_{2} \mathrm{O}$. Figure 3-4 shows the measured solubility limits for plutonium in carbonate solutions at $\mathrm{pH}$ greater than 12 compared with measured supernatant concentrations of plutonium in DSTs (Van Vleet 1993).

These data provide strong evidence that sorption/desorption phenomena control the plutonium concentration in the supernatant solutions rather than the solubility of $\mathrm{PuO}_{2} \cdot \mathrm{XH}_{2} \mathrm{O}$.

The effects of radiolysis on plutonium chemistry with respect to the criticality safety issue are discussed in Serne et al. 1995. Alpha emissions from the decay of ${ }^{239} \mathrm{Pu}$ produce free radicals which are powerful reduction-oxidation (redox) agents. These free radicals may induce plutonium redox reactions resulting in the formation of various valence species. Such self-catalyzed plutonium reactions are categorized as radiolytic effects. Radiolysis has been analyzed in terms of the ability to provide a redox-driven solubility transport and reconcentration mechanism.

There are only a limited number of experiments in which radiolysis effects have been studied under near neutral or slightly alkal ine conditions as summarized in Serne et al. (1996). Because there is only limited radiolysis experimental data relevant for very highly alkaline and ionic strength solutions that are typical of Hanford Site high-level waste supernatants, the affects cannot be easily quantified with respect to conditions in the waste tanks. However, it is concluded that none of the observed soluble plutonium concentrations in any experiments (or from the characterization of actual waste samples) exceed a plutonium concentration of $0.13 \mathrm{~g} / \mathrm{L}$ which is well below the subcritical concentration of $2.6 \mathrm{~g} \mathrm{Pu} / \mathrm{L}$ (Serne et al. 1996). 
Figure 3-3. Model Sorption and Desorption Isotherms for Plutonium Sorption on Metal Oxyhydroxides.

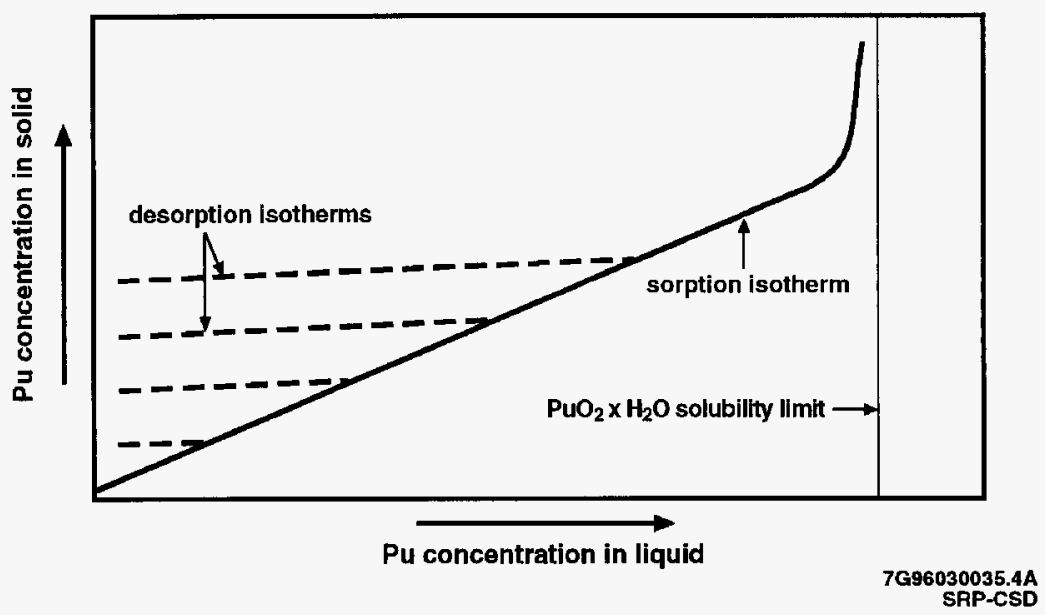

Figure 3-4. Plutonium Oxyhydroxide Solubilities Compared with Measured Plutonium Concentrations in Double-She11 Tank Supernate Solutions for Various Carbonate Concentrations.

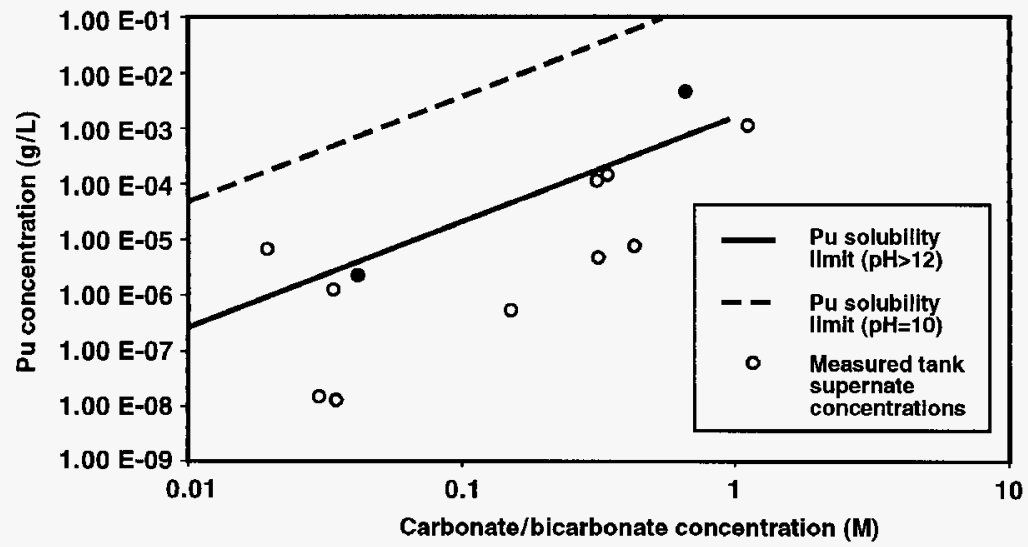


WHC-SD-WM-TI-725

Revision 0

\subsection{CONCLUSIONS}

A multidisciplinary team of senior technical personnel has reviewed the criticality safety of the Hanford Site waste tanks. The team concluded that the detailed and documented nucleonics-related studies underlying the criticality safety basis of the waste tanks were technically sound and conservative.

In addition, detailed technical analyses and modeling have been performed to better understand the behavior of fissile material in oxyhydroxide solids (sludge) under current safe storage conditions in the waste tanks. Physical and chemical forces that could separate stored fissile materials from the associated neutron moderators (e.g., iron, chromium, aluminum) under alkaline conditions have also been modeled to demonstrate that mass transport, even under extreme thermal gradients, will not lead to concentrations of fissile material that significantly reduce the existing margin of subcriticality (Serne et al. 1996).

As a result of the detailed technical analysis and modeling, Figure 3-2 identifies the relationship of the phenomena and mechanistics associated with the criticality safety of the waste tanks. The chemistry of the fissile material under neutralized high-level waste conditions is very complex, notably so after decades of storage and elevated temperature. Although fissile material can potentially follow several mechanistic pathways under initial neutralization and over an extended time, several other conditions must still occur before there is a potential for an accidental criticality. Figure 3-2 summarizes these conditions noting that a separation mechanism must exist to separate the fissile material from the neutron absorbing, oxyhydroxide (sludge) particles. Even then, sufficient concentration and a favorable geometry must exist before there is a potential for criticality.

In summary, the phenomena and mechanistic studies performed to evaluate the criticality safety of the waste tanks show that under the existing waste tank conditions, the fissile material cannot become separated and/or concentrated from the neutron absorber oxyhydroxide solids to the extent that it results in a significant reduction of the existing margin of subcriticality (Serne et a1. 1996). In addition, the favorable neutronics of the waste tanks support the finding that an accidental criticality is incredible under existing waste tank conditions.

Note, however, that this finding applies only to existing waste tank conditions. Although the phenomena and mechanistics studies also support forthcoming retrieval operations (i.e., retrieval of waste from tank 241-C-106), future operational activities must be evaluated against the technical-based limits and controls to ensure future subcritical conditions. 
WHC-SD-WM-TI-725

Revision 0

This page intentionally left blank. 
WHC-SD-WM-TI-725

Revision 0

\subsection{REFERENCES}

Alberts, J. J., and K. A. Orlandini, 1981, Laboratory and Field Studies of the

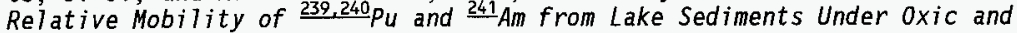
Anoxic Conditions, Geochimica et Cosmochimica Acta, 45, pp. 1933-1938.

Anderson, J. D., 1990, A History of the 200 Area Farms, WHC-MR-0132, Westinghouse Hanford Company, Richland, Washington.

Antizzo, J. V., 1995, Documentation of Agreements Reached with the Department of Energy/Richland Operations Office and the Westinghouse Hanford Company on the Path Forward for the Resolution of the Hanford Tanks Criticality Safety Issue (1etter to J. E. Kinzer, U.S. Department of Energy, Richland Operations Office, July 14), U.S. Department of Energy-Headquarters, Washington, D.C.

Braun, D. 3., L. D. Muhlestein, T. B. Powers, and M. D. Zentner, 1994, High-Level Waste Tank Subcriticality Safety Assessment, WHC-SD-WM-SARR-003, Rev. 0, Westinghouse Hanford Company, Richland, Washington, $p p$. B-9 to $B-20$.

Brevick, C. H., 1995, Tank Waste Source Term Inventory Validation - Volumes I \& II, WHC-SD-WM-ER-400, Rev. 0, Westinghouse Hanford Company, Richland, Washington.

Carter, R. D., G. R. Kiel, and K. R. Ridgway, 1970, Criticality Handbook, Vol. II, ARH-600, Section III, pp. A.8.100-1, Atlantic Richfield Hanford Company, Richland, Washington.

Delegard, C. W., G. S. Barney, and S. A. Gallagher, 1984, Effects of Hanford High-Level Waste Components on the Solubility and Sorption of Cobalt, Strontium, Neptunium, Plutonium, and Americium, Geochemical Behavior of Disposal Radioactive Waste, G. S. Barney, J. D. Navratil, and

W. W. Schulz, Eds., ACS Symposium Series 246, American Chemical Society, p. 95 .

Gephart, R. E., and R. E. Lundgren, 1995, Hanford Tank Cleanup: A Guide to Understanding the Technical Issues, PNL-10773, Pacific Northwest Laboratory, Richland, Washington.

DOE, 1988, Site Characterization Plan, Reference Repository Location, Hanford Site, Washington, DOE/RW-0164, Vol. 3, U.S. Department of Energy, Washington, D.C., pp. 4.1-106.

Ecology, EPA, and DOE, 1996, Hanford Federal Facility Agreement and Consent Order, as amended, Washington State Department of Ecology, U.S. Environmental Protection Agency, and U.S. Department of Energy, 0lympia, Washington.

Hanlon, B. M., 1993, Tank Farm Surveillance and Waste Status Summary Report for August 1993, WHC-EP-0182-65, West inghouse Hanford Company, Richland, Washington. 
Hanlon, B. M., 1996, Waste Tank Summary Report for Month Ending February 29, 1996, WHC-EP-0182-95, Westinghouse Hanford Company, Richland, Washington.

Hanson, G. L. and J. R. La Riviere, 1981, Safety Analysis Report Stabilization of Single Shell Waste Storage Tanks By Salt Well Jet Pumps, Rockwell Hanford Operations, Richland, Washington.

Jungfleisch, F. M., 1993, Preliminary Estimation of the Waste Inventories in Hanford Tanks Through 1980, WHC-SD-WM-TI-057, Rev. 0-A, Westinghouse Hanford Company, Richland, Washington.

Kady, T. M., and 0. C. Groff, 1983, Aging Waste Tank Facility Description Manual, FDM-T-200-00003, Westinghouse Hanford Company, Richland, Washington.

Kim, J. I., C. Lierse, and F. Baumgartner, 1983, Complexation of Plutonium(IV) Ion in Carbonate-Bicarbonate Solutions, Plutonium Chemistry, W. T. Carnel1 and G. R. Choppin, Eds., ACS Symposium Series 216, American Chemical Society, p. 317.

Laitinen, H. A., 1960, Chemical Analysis, McGraw-Hill Book Company, Inc., New York, New York, p. 169.

Lindsay, W. L., 1979, Chemical Equilibria in Soils, John Wiley \& Sons, New York, pp. 40 and 135.

Rai, D., R. J. Serne, and G. A. Moore, 1980, Solubility of Plutonium Components and their Behavior in Soils, Soil Science Society of America Journa?, 44, 490 .

Roetman, V. E., S. P. Robyler, and H. Toffer, 1994, Estimation of Plutonium in Hanford Site Waste Tanks, Based on Historical Records, WHC-EP-0793, Rev. 0, Westinghouse Hanford Company, Richland, Washington.

Rogers, C. A., 1993, CSER 92-009: An Analytical Model for Evaluating Subcritical Limits for Waste in Hanford Site Storage Tanks, WHC-SD-SQA-SA-20356, Rev. 0, Westinghouse Hanford Company, Richland, Washington.

Rogers, C. A., 1996, CSER 96-010: Criticality Parameters for Tank Waste Evaluation, WHC-SD-SQA-CSA-507, Rev. 0, Westinghouse Hanford Company, Richl and, Washington.

Serne, R. J., G. A. Whyatt, S. V. Mattigod, Y. Onishi, P. G. Doctor, B. N. Bjornstad, M. R. Powe11, L. M. Liljegren, J. H. Westsik, N. J. Aimo, K. P. Recknagle, G. R. Golcar, T. B. Miley, G. R. Holdren, D. W. Jeppson, R. K. Biyani, and G. S. Barney, 1996, Fluid Dynamic Particulate Segregation, Chemical Processes, and Natural Ore Analog Discussions that Relate to the Potential for Criticality in Hanford Tanks, WHC-SD-WM-TI-757, Rev. 0, West inghouse Hanford Company, Richland, Washington. 
Sullivan, L. H., 1995, A Safety Assessment for Proposed Pump Mixing Operations to Mitigate Episodic Gas Releases in Tank 241-SY-101: Hanford Site, Richland, Washington, LA-UR-92-3196 Rev. 14, Los Alamos National Laboratory, Los Alamos, New Mexico.

Toth, L. M., H. A. Friedman, and M. M. Osborne, 1981, "Plymerization of Pu(IV) in Aquous Nitric Acid Solution," J. Inorg. Nucl. Chem, 43, (11), pp. 2929-2934.

Tusler, L. A., 1995, Configuration Management Plan for Tank Farm Plutonium Inventory System, WHC-SD-WM-CSCM-007, Rev. 4, Westinghouse Hanford Company, Richland, Washington.

Van Vleet, R. J., 1993, Radionulcide and Chemical Inventories for the Double She 77 Tanks, WHC-SD-WM-TI-543, Rev. 1, Westinghouse Hanford Company, Richland, Washington.

Waltar, A. E., H. Babad, G. S. Barney, R. S. Felt, J. Greenborg, L. H. Rodgers, R. J. Serne, G. A. Whyatt, D. R. Bratzel, and E. J. Lipke, 1996, Criticality Safety Assessment of Tank 241-C-106 Remediation, WHC-SD-W320-CSA-001, Rev. 0, Westinghouse Hanford Company, Richland, Washington.

Whyatt, G. A., R. J. Serne, S. V. Mattigod, Y. Onishi, M. R. Powell, 3. H. Westsik, Jr., L. M. Liljegren, G. R. Golcar, K. P. Recknagle, P. M. Doctor, V. G. Zhirnov, J. Dixon, D. W. Jeppson, and G. S. Barney, 1996, The Potential for Criticality in Hanford Tanks Resulting from Retrieval of Tank Waste, (Draft), Pacific Northwest National Laboratory, Richland, Washington.

Yamaguchi, T., Y. Sakamoto, and T. Ohnuki, 1994, Effect of Complexation on Solubility of Pu(IV) in Aqueous Carbonate System, Radiochimica Acta, 66/67.

Yariv, S., and H. Cross, 1979, Geochemistry of Colloid Systems, SpringerVerlag, Berlin, Heidelberg, New York, New York, p. 178. 
WHC-SD-WM-T I-725

Revision 0

This page intentionally left blank. 
WHC-SD-WM-TI-725

Revision 0

\section{APPENDIX A}

\section{PLUTONIUM INVENTORY FOR HANFORD SITE SINGLE-SHELL TANKS}

A-1 
WHC-SD-WM-TI-725

Revision 0

This page intentionally left blank. 


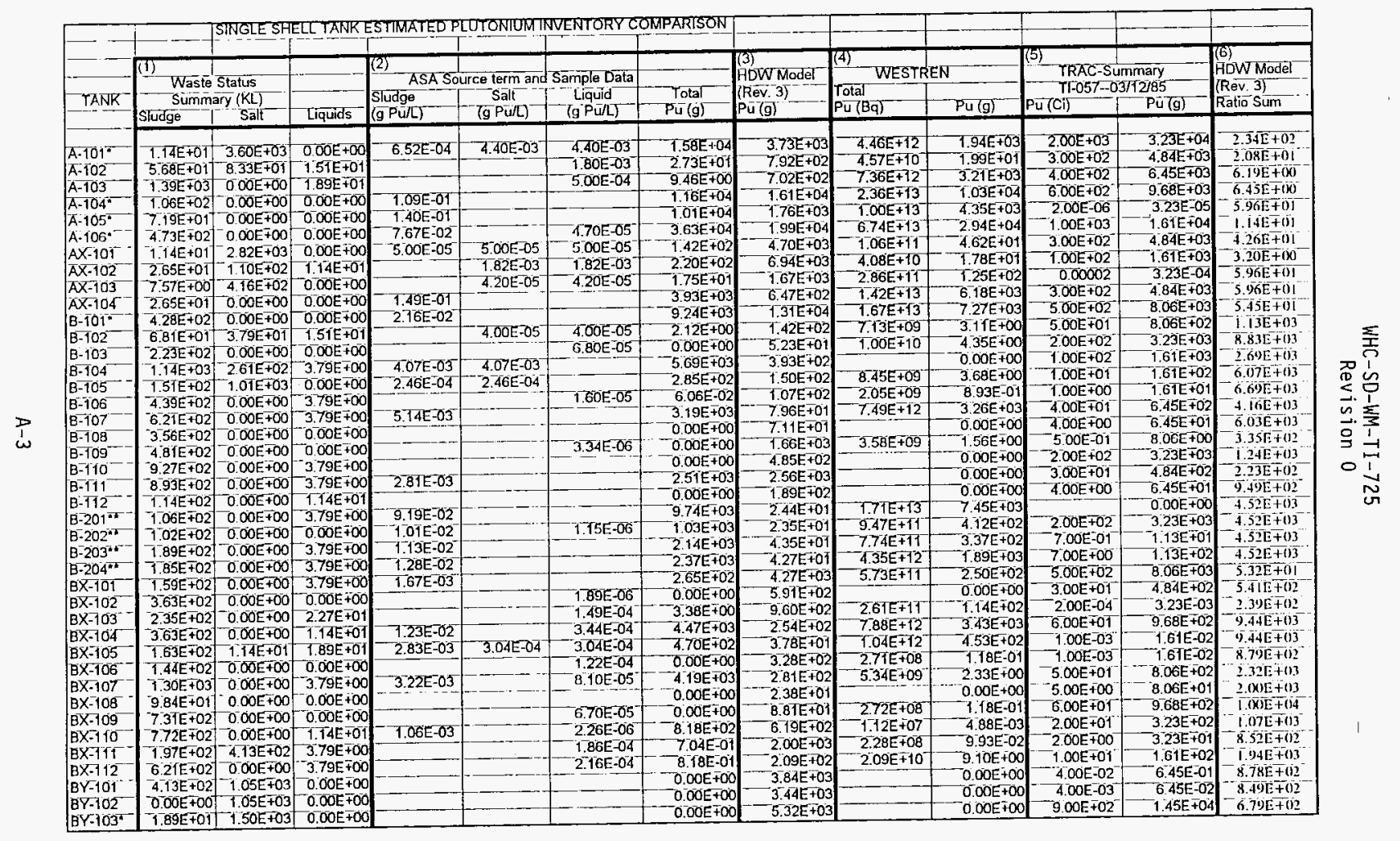




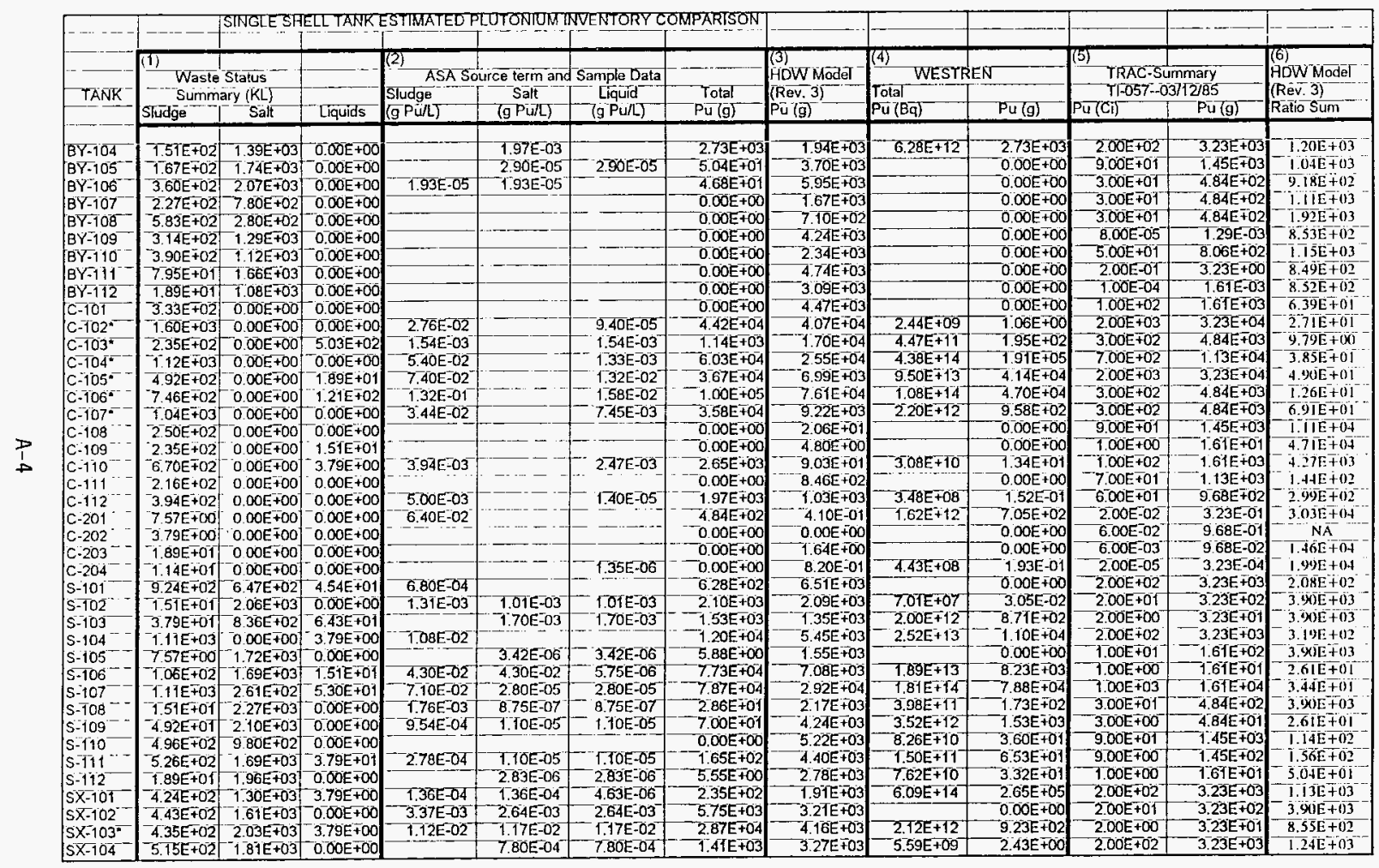




\begin{tabular}{|c|c|c|c|c|c|c|c|c|c|c|c|c|c|}
\hline & & STNGLE SHI & LL TANKE & ESTIMATEDP & COTONIUMII & IVENTORYC & $O N$ & & & & & & \\
\hline \multirow[b]{3}{*}{ TANK - } & (1) & & & (2) & & & & \multirow{4}{*}{$\begin{array}{l}(3) \\
\text { HoW Madel } \\
\text { (Rev. 3) } \\
\text { Pu (g) }\end{array}$} & (4) & & (5) & & \multirow{4}{*}{$\begin{array}{l}(6) \\
\text { HoW Model } \\
\text { (Rev. 3) } \\
\text { Ratio Sum }\end{array}$} \\
\hline & Waste & Status & & ASASO & urce term and & Sample Data & & & \multicolumn{2}{|c|}{ WESTREN } & \multirow{2}{*}{\multicolumn{2}{|c|}{$\begin{array}{l}\text { TRAC-Sumimary } \\
\text { TI-057-03/12/85 }\end{array}$}} & \\
\hline & $\begin{array}{l}\text { Summ } \\
\text { Sludge }\end{array}$ & ary $(K L)$ & & Sludge & $\begin{array}{c}\text { Salt } \\
(\mathrm{g} P \mathrm{P} / \mathrm{C})\end{array}$ & Liquid & Total & & Total & Pu $(0)$ & & & \\
\hline & & Salt & Liquids & & & & & & & $P 0 \operatorname{9g}$ & & & \\
\hline$S X-105$ & $2.7 \overline{6 E}+02$ & $2.31 \mathrm{E}+03$ & $0.00 \mathrm{E}+00$ & $1.26 \mathrm{E}-04$ & 5.14E-06 & $5.14 \mathrm{E}-06$ & $4.67 E+01$ & $4.05 E+03$ & $2.38 \mathrm{E}+07$ & T.OAE-02 & $2.00 E+01$ & $3.23 \mathrm{E}+02$ & $1 . \overline{28 E+03}$ \\
\hline 66 & $4.54 E+01$ & $1.76 E+03$ & $2.31 E+02$ & $5.00 E-03$ & 5.66E-04 & $5.66 \mathrm{E}-04$ & 7.35E+03 & $2.73 E+03$ & & $0.00 E+00$ & $3.00 E-04$ & $4.84 E-03$ & $8.22 \mathrm{E}+02$ \\
\hline $\begin{array}{l}s \bar{s}-107 \\
\text { sx-108 }\end{array}$ & $3.94 E+02$ & $0.00 E+C O O$ & $000 E+00$ & & & & $0.00 E+00$ & $2.65 E+03$ & $3,39 E+08$ & $1.48 E \div 01$ & $3.00 \mathrm{E}+02$ & $4.84 E+03$ & $2.53 \overline{\mathrm{E}+03}$ \\
\hline $\begin{array}{l}S \overline{x-108} \\
5 \overline{x-109}\end{array}$ & $3.29 \mathrm{E}+02$ & $0.00 E+00$ & $0.00 E+00$ & & & & $0.00 E+00$ & 1.04E+03 & & O.OOEETOO & $300 E+02$ & $4.84 E+03$ & $=\frac{9.93 \mathrm{E}+02}{4.73 \mathrm{E}+03}$ \\
\hline $\begin{array}{l}S \\
S\end{array}$ & $\begin{array}{l}0.00 E+00 \\
2.35 E+02\end{array}$ & $9.46 \mathrm{E}+\mathrm{O} 2$ & ODOE+OO & & & & $0.00 E+00$ & T.81E+03 & & $0.00 E+00$ & $\begin{array}{l}2.00 E+02 \\
300 E+02\end{array}$ & $\begin{array}{r}3.23 \mathrm{E}+03 \\
-4.84 \mathrm{E}+03\end{array}$ & $\begin{array}{l}4.73 \mathrm{E}+03 \\
1.84 \mathrm{E}+03\end{array}$ \\
\hline $\begin{array}{l}S X-110 \\
S X-111\end{array}$ & $\begin{array}{r}2.35 E+02 \\
-4.73 E+02\end{array}$ & $0.00 E+\infty 0$ & $0,00 E+00$ & $151 \mathrm{E}-03$ & & & $\begin{array}{l}0.00 E+00 \\
714 E+02\end{array}$ & $\begin{array}{r}3.35 \mathrm{E}+02 \\
-5.05 \mathrm{E}+02\end{array}$ & $1.41 E+12$ & $\begin{array}{l}0.00 E+00 \\
6.14 E+02\end{array}$ & $400 \mathrm{O}+02$ & $\begin{array}{l}4.84 \mathrm{E}+03 \\
6.45 \mathrm{E}+03\end{array}$ & $\begin{array}{l}1.84 E+03 \\
1.95 E+03\end{array}$ \\
\hline 112 & $\begin{array}{l}4.3 \mathrm{E}+02 \\
3.48 \mathrm{E}+02\end{array}$ & $0.00 E+00$ & $\begin{array}{r}0.00 E+00 \\
0.00 E+00\end{array}$ & $1.51 E=0.3$ & & $1.35 \mathrm{E}-06$ & $\begin{array}{l}7.14 \mathrm{E}+02 \\
0.00 \mathrm{E}+00\end{array}$ & $\begin{array}{r}5.05 E+02 \\
-3.02 E+02\end{array}$ & & $0.00 E+\infty 0$ & $2,00 \mathrm{E}+02$ & $3.23 E+03$ & $2.16 \mathrm{E}+03$ \\
\hline$\$ \times-113$ & $984 E+01$ & $0.00 E+00$ & $0.00 E+00$ & & & & $0.00 E+00$ & $202 E+00$ & & $0.00 E+00$ & $6.00 \mathrm{E}+01$ & $968 \mathrm{E}+02$ & $5.02 \mathrm{E}+04$ \\
\hline $5 \times-114$ & G.85E+02 & $0.00 \mathrm{E}+00$ & $0.00 \mathrm{E}+00$ & & & & $0.00 E+00$ & $-1.30 E+03$ & & $0.00 E+\infty$ & $4.00 E+02$ & $6.45 E \mp 03$ & 1 $15 E+03$ \\
\hline 115 & 4.54EF01 & $0.00 E+00$ & $0.00 E+00$ & 1.94E-01 & & & $8.80 \mathrm{E}+03$ & $6.09 \mathrm{E}+01$ & $1.6 \overline{8} E+13$ & $7.32 E+03$ & 02 & 1.61EF03 & $1.53 E+03$ \\
\hline$T-$ & 3.82E+02 & $0.00 E+00$ & $-379 E+\infty 0$ & & & $4.70 \mathrm{E}-05$ & $1.78 \mathrm{E}-01$ & $1.14 E+04$ & 1.07EFo9 & 4.66E-01 & 5.00E-05 & $8.06 \mathrm{E}-04$ & $963 \mathrm{E}+00$ \\
\hline$T-102$ & $7.19 E+01$ & $0.0 \overline{0}+00$ & $4.92 \mathrm{E}+01$ & $1.26 \mathrm{E}-03$ & & $2.90 \mathrm{E}-05$ & $9.20 \mathrm{E}+01$ & $1,98 \mathrm{E}+03$ & & $0.00 E+00$ & $1.00 E-06$ & 1.61E-05 & $2.43 E+01$ \\
\hline$T-103$ & $8.71 \mathrm{E}+01$ & $0.00 E+00$ & 151E+01 & & & 1.40E-05 & $212 \mathrm{E}-01$ & $1.98 E+03$ & & $0.00 E+00$ & 1.00E-01 & $1.61 E+00$ & $2.23 E+11$ \\
\hline$T-104^{\circ}$ & $1.67 E+03$ & $0.00 E+00$ & 1. $\sqrt{4 E}+01$ & $7.40 \mathrm{E}-03$ & & $1,52 E-04$ & $1.24 \mathrm{E}+04$ & $4.42 E+02$ & 2.19E+13 & $9.54 E+03$ & 1.00E+02 & 1.61E+03 & $182 \mathrm{E}+03$ \\
\hline $\mid \begin{array}{l}T-10 \\
T-10\end{array}$ & $3.71 \mathrm{E}+\mathrm{C2}$ & $0.00 \mathrm{E}+00$ & $0 . \overline{O O E}+\overline{0}$ & 4.30E-03 & & $2.20 \mathrm{E}-03$ & 1.59EF03 & $1.02 E+02$ & & OOOE+OO & +02 & $3.23 \mathrm{E}+03$ & \\
\hline $\begin{array}{l}T-1 \\
T-1\end{array}$ & $\begin{array}{l}7.19 \mathrm{E}+01 \\
6.47 \mathrm{E}+02\end{array}$ & $0.00 E+00$ & $7.57 \mathrm{E}+00$ & $\begin{array}{r}8.20 \mathrm{E}-03 \\
4.20 \mathrm{E}-03\end{array}$ & & $\begin{array}{l}1.79 \mathrm{E}-04 \\
5.31 \mathrm{E}-03\end{array}$ & $591 E+02$ & 1.7BE+03 & $\begin{array}{l}1.58 E+12 \\
151 E+10\end{array}$ & $\begin{array}{l}6.88 \mathrm{~B}+02 \\
-6.58 \mathrm{E}+00\end{array}$ & ito1 & $\begin{array}{r}3.23 E+02 \\
-8.06 E+02\end{array}$ & $\begin{array}{l}2.87 \mathrm{E}+01 \\
4.27 \mathrm{E}+03\end{array}$ \\
\hline $\begin{array}{l}T-107 \\
T=108\end{array}$ & $\begin{array}{r}6.47 \mathrm{E}+02 \\
-1.67 \mathrm{E}+02\end{array}$ & $\begin{array}{c}0.00 E+00 \\
0.00 E+00\end{array}$ & $\begin{array}{r}3.4 \mathrm{E} E+01 \\
-0.00 \mathrm{E}^{+}+00\end{array}$ & $4.20=-03$ & & $\begin{array}{r}5.31 \mathrm{E}-03 \\
1.22 \mathrm{E}-04\end{array}$ & $\begin{array}{l}2.90 E+03 \\
0.00 E+00\end{array}$ & $\begin{array}{r}8.26 E+01 \\
3.50 E+01\end{array}$ & $1.51 E+10$ & $\begin{array}{r}6.58 E+\infty 0 \\
-0.00 E+00\end{array}$ & $+\infty+\infty$ & $8.06 \mathrm{E}+01$ & $4.81 E+03$ \\
\hline $\mathrm{T}-109^{\circ}$ & $2.20 E+02$ & $0.00 \mathrm{E}+00$ & $0.00 E^{-}+00$ & & & $5.40 E-05$ & $0.00 E+00$ & $6.26 \mathrm{E}+01$ & & $0.00 E+00$ & $5.00 E=01$ & $8.06 \mathrm{E}+00$ & 5. $13 E+03$ \\
\hline$T-11$ & $1.42 E+03$ & $0.00 E+00$ & $1.14 E+01$ & & & $3.77 \mathrm{E}-06^{-}$ & $4.2 \mathrm{BE}-02$ & $3.24 \mathrm{E}+02$ & & $0.00 E+00$ & $200 E^{\circ} 02$ & $3.23 E+03$ & $2.87 \mathrm{E}+03$ \\
\hline$T-111$ & 1.69E+03 & $0.00 \mathrm{E}+00$ & $0.00 E+00$ & $3.94 \mathrm{E}-03$ & & $135 E-06$ & $6,65 E+03$ & $3.70 \mathrm{E}+02$ & & $0.00 E+C O$ & $1.00 \mathrm{E}+02$ & $-61 E+03$ & $292 \mathrm{E}+03$ \\
\hline$T-112$ & $2.27 E+02$ & $0.00 E+00$ & $2.65 E \mp 01$ & & & $3.00 \mathrm{E}-05$ & 7.95E-01 & $4,46 E+01$ & 1.81E+09 & $7.88 E-01$ & $2.00 E+02$ & $32 \overline{3} E+03$ & $2.15+03$ \\
\hline$T=$ & $10 \overline{6} E+02$ & $0.00 E+00$ & $3.79 E+00$ & & & & $0.00 \mathrm{E}+00$ & $2.4 \overline{4} E+0 \mathrm{~d}$ & & $0.00 E+00$ & & $0.00 \mathrm{E}+00$ & $452 \mathrm{E}+03$ \\
\hline$T-202$ & $7.95 E+0 t$ & $0.00 E+30$ & $0.00 E+00$ & & & & $0.00 E+00$ & 1. $8 \overline{3} \mathrm{~F}+01$ & & $0.00 E+00$ & $3.00 \mathrm{E}-01$ & $4.84 \mathrm{E}+00$ & $452 \mathrm{E}+03$ \\
\hline$T$ & $1.32 \mathrm{E}+02$ & $000 E+00$ & $0.00 E+00$ & & & & $0.00 E+00$ & 3.05E 001 & & $0.00 E+00$ & $3.00 E+00$ & $484 E+01$ & $4.52 E+03$ \\
\hline T-204 & $1.44 E^{2}+02$ & $0.00 E+00$ & $0.00 E+00$ & 1.51E-03 & & $1.52 E-03$ & $2.17 \mathrm{E}+02$ & 3.31E+01 & 45AE+10 & $1.98 E+01$ & & OOOE +OO & A $52 \mathrm{E}+03$ \\
\hline$T X-10 T$ & $3.8 \mathrm{E}+02$ & $0.00 E+00$ & $1.14 E+01$ & & & 3.22E-03 & $365 E+01$ & $5.01 E+03$ & & $0.00 E+00$ & $3.00 \mathrm{E}-05^{-}$ & $484 E-04$ & $6.14 E+01$ \\
\hline$T X-102$ & $0.00 E+00$ & $8.21 E+02$ & $0.00 E+00$ & & & & $0.00 E+\infty 0$ & B.79E +02 & & $0.00 E+00$ & $=08$ & $1,45 E-06$ & $9.44 E+03$ \\
\hline$T X-103$ & $-5.94 E+02$ & $O 00 E+00$ & $0.00 E+00$ & & & $257 E-04$ & $0.00 E+00$ & $3.71 \mathrm{E}+02$ & $8.08 E+11$ & $E+02$ & $=07$ & 145E-05 & $5.03 \mathrm{E}+03$ \\
\hline $7 \times-104$ & $-0.00 E+000$ & $2.42 E+02$ & $-3.79 E+00$ & & 1.39E-03 & 139E-03 & $3.42 E+02$ & $1.99 \mathrm{E}+02$ & 1.94E +12 & B. $45 E+02$ & $3.00 E-04$ & $484 E=03$ & $944 E+63$ \\
\hline & $0.00 E+00$ & $2.31 E+03$ & $0.00 E+00$ & & $5.66 E=04$ & $-566 \mathrm{E}=04$ & $1.30 \mathrm{E}+03$ & 2.54EF03 & & $0.00 E+00$ & 04 & $6.45 E-03$ & $9.44 E+13$ \\
\hline$T X-106$ & $0.00 E+00^{\circ}$ & $171 \mathrm{E}+03$ & $0.00 E+00$ & & $2.00 \mathrm{E}-05^{-}$ & - 2.00E-05 & $3.43 E+01$ & $1.37 \mathrm{E}+03$ & & OOOE +00 & $3.00 E-08$ & $4.84 E-07$ & A.4EFU3 \\
\hline$T X-107$ & $0.00 E+00$ & $1.32 E+02$ & $3.79 E+00$ & & $3.92 E-03$ & - 392E-03 & $533 E+02$ & $2.49 E+01$ & $136 E+13$ & $5.92 E+03$ & & $-1.45 \mathrm{E}-05$ & $9.445+03$ \\
\hline$T x-108$ & $0.00 E+00$ & $5.07 E+02$ & $000 E+00$ & & $7.90 E-05$ & - $790 \mathrm{E}-05$ & $401 \mathrm{E}+01$ & $3.95 E+02$ & & $0.00 E+00$ & $6.00 E-01$ & $968 E+00$ & $1.52 \mathrm{E}+14$ \\
\hline$T \times-109$ & $0.00 E+00$ & $1.45 E+03$ & $0.00 E+00$ & & 1. $\{2 \mathrm{E}-03$ & $1.12 \mathrm{E}=03$ & $163 E+03$ & $3.78 E+02$ & & O.COEFDO & $200 E+02$ & $3.23 E+03$ & $1.82 \mathrm{E}+109$ \\
\hline$T X-110^{-}$ & $0.00 E+00$ & $1,75 \mathrm{E}+03$ & $0.60 E+00$ & & 7.80E-05 & 7.BOE-05 & $136 E+02$ & $1.79 E+03$ & & $0.00 E+\infty 0$ & $1.00 \mathrm{E}+01^{-1}$ & $1.61 E+02$ & $1.50 \mathrm{E}+03$ \\
\hline$T X-111$ & $0.00 E+00$ & 1. $A 0 E+03$ & $0.00 E+00$ & & & & $0.00 E+00$ & $141 \mathrm{E}+03$ & & $0.00 E+00$ & $1.00 E^{-}+00$ & $1.61 E+01$ & 1. $16 \mathrm{E}+113$ \\
\hline$T X=112$ & $0.00 E+00$ & $2.46 E+03$ & $0.00 E+00$ & & & & $0.00 E+00$ & $262 E+03$ & & $0.00 E+00$ & $=02$ & $968 E-01$ & $5.03 \mathrm{E}+03$ \\
\hline$T X-113$ & $0.00 E+00$ & $230 \mathrm{E}+03$ & $0.00 \mathrm{E}+00$ & & & & $0.00 E \mp 00$ & $1.99 E+03$ & & $0.00 E+\infty$ & $5.00 E+01$ & $806 \mathrm{E}+02$ & $1.18 \mathrm{E}+03$ \\
\hline $1 T X-114$ & $-0.00 E+00$ & $2.02 \mathrm{E}+03$ & $0.00 E+00$ & & & & $0.00 E+00$. & $210 \mathrm{ET} 3$ & & $0.00 E+00$ & $5.00 E+00$ & B.06E+01 & $4.73 E+03$ \\
\hline
\end{tabular}




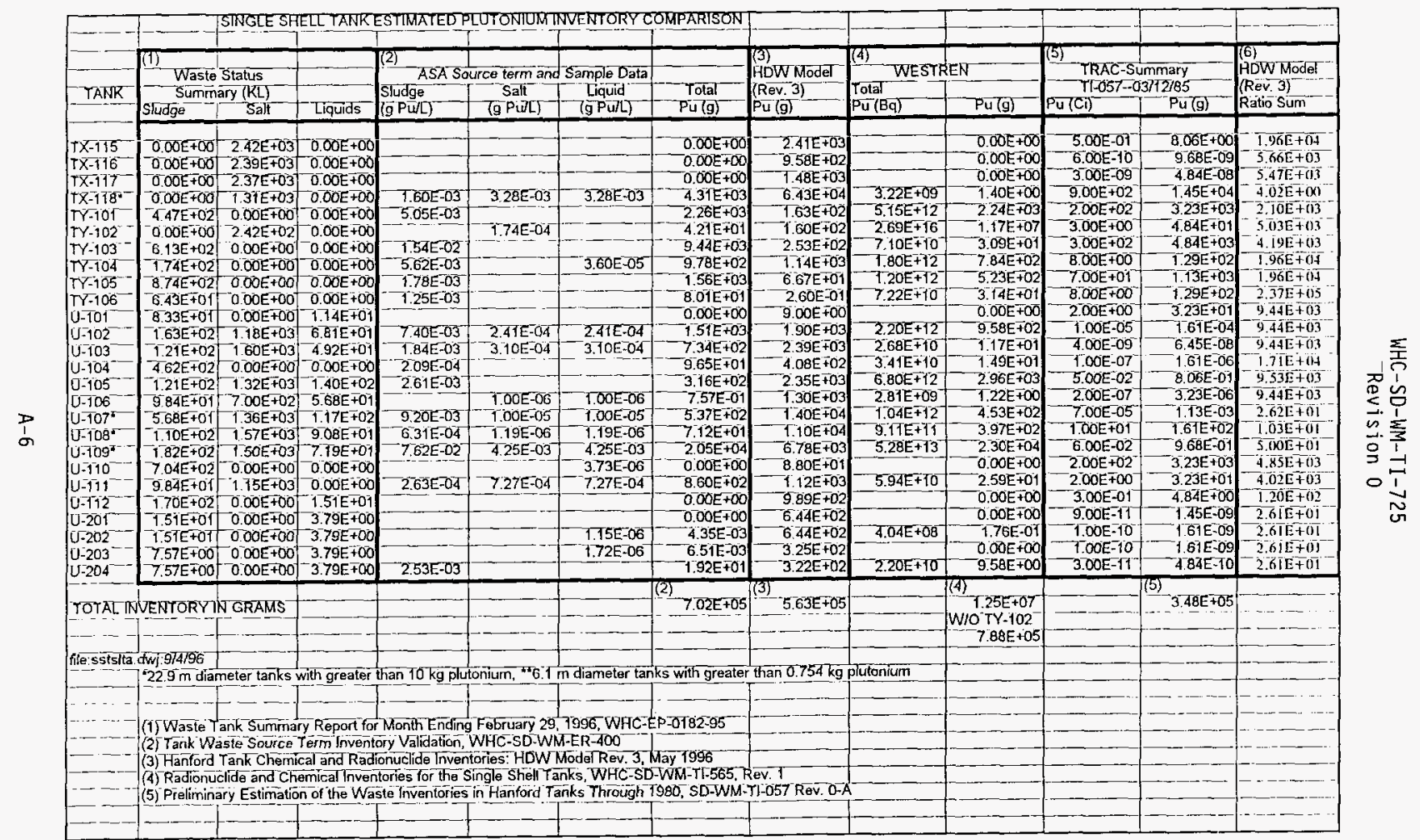


WHC-SD-WM-TI-725

Revision 0

\section{A1.0 REFERENCES}

Agnew, S. F., 1996, Hanford Tank Chemical and Radionuclide Inventories: HOW Mode7, Rev. 3, LA-UR-96-858, Los Alamos National Laboratory, Los Alamos, New Mexico.

Brevick, C. H., 1995, Tank Waste Source Term Inventory Validation, WHC-SD-WM-ER-400, Rev. 0, Westinghouse Hanford Company, Richland, Washington.

Hanlon, B. M., 1996, Waste Tank Summary Report for Month Ending February 29, 1996, WHC-EP-0182-95, Westinghouse Hanford Company, Richland, Washington.

Jungfleisch, F. M., 1993, Preliminary Estimation of the Waste Inventories in Hanford Tanks Through 1980, WHC-SD-WM-TI-057, Rev. 0-A, Westinghouse Hanford Company, Richland, Washington.

Van Vleet, R. J., 1993, Radionulcide and Chemical Inventories for the Double She 77 Tanks, WHC-SD-WM-TI-543, Rev. 1, Westinghouse Hanford Company, Richland, Washington. 
WHC-SD-WM-TI-725

Revision 0

This page intentionally left blank. 
WHC-SD-WM-TI-725

Revision 0

\section{APPENDIX B}

\section{PLUTONIUM INVENTORY FOR HANFORD SITE DOUBLE-SHELL TANKS}


WHC-SD-WM-TI-725

Revision 0

This page intentionally left blank. 
WHC-SD-WM-TI-725

Revision 0

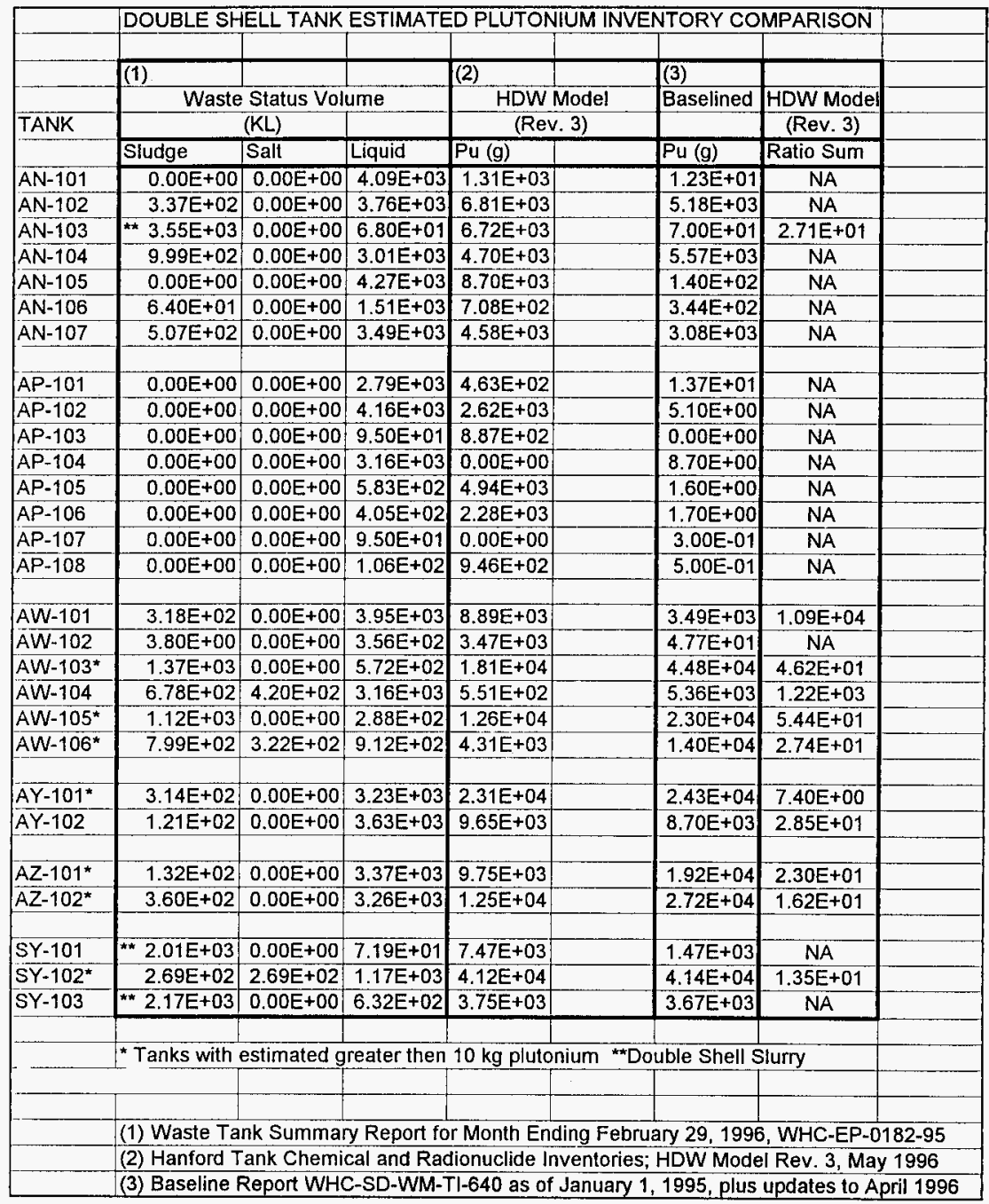


WHC-SD-WM-TI-725

Revision 0

\section{B1.0 REFERENCES}

Agnew, S. F., 1996, Hanford Tank Chemical and Radionuclide Inventories: HDW Mode7, Rev. 3, LA-UR-96-858, Los Alamos National Laboratory, Los Alamos, New Mexico.

Hanlon, B. M., 1996, Waste Tank Summary Report for Month Ending February 29 , 1996, WHC-EP-0182-95, Westinghouse Hanford Company, Richland, Washington.

Tusler, L. A., 1995, Double-She77 Tanks Plutonium Inventory Assessment, WHC-SD-WM-TI-640, Rev. 0, Westinghouse Hanford Company, Rich 1 and, Washington. 